Esta obra está bajo una Licencia Creative Commons Atribución-

NoComercial-CompartirIgual 4.0 internacional

Geometrías perdurables. El caso de las placas grabadas líticas del Golfo San Matías (provincia de Río Negro) y su contextualización en la Patagonia argentina

Danae Fiore, Agustín Acevedo, Cristian M. Favier Dubois

Relaciones, 46(2), e022, julio-diciembre 2021

ISSN 1852-1479 | https://doi.org/10.24215/18521479e022

https://revistas.unlp.edu.ar/relaciones

ISSN 0325-2221 (versión impresa)

Sociedad Argentina de Antropología (SAA)

Buenos Aires I Argentina

\title{
GEOMETRÍAS PERDURABLES. EL CASO DE LAS PLACAS GRABADAS LÍTICAS DEL GOLFO SAN MATÍAS (PROVINCIA DE RÍO NEGRO) Y SU CONTEXTUALI- ZACIÓN EN LA PATAGONIA ARGENTINA
}

Danae Fiore*, Agustín Acevedo** y Cristian M. Favier Dubois ${ }^{* * *}$

Fecha de recepción: 7 de diciembre de 2020

Fecha de aceptación: 23 de junio de 2021

\section{RESUMEN}

Este trabajo analiza un conjunto de placas grabadas procedentes del Golfo San Matías (provincia de Río Negro) con el objeto de evaluar recurrencias de diseño que indiquen la presencia de reglas de ornamentación y/o codificación de información visual entre las poblaciones cazadoras-recolectoras que las produjeron y utilizaron. Posteriormente, se desarrollan comparaciones sistemáticas con 170 placas procedentes de Patagonia y otras regiones de Argentina, utilizando como indicador principal la presencia de tipos de motivos compartidos. Los datos se evalúan a la luz de un modelo teórico con expectativas que vinculan variabilidad/estandarización de diseños, laxitud/estructuración ornamental y heterogeneidad/redundancia informativa. Los resultados demuestran que las placas mantienen una baja estandarización de los diseños, compatible con una función comunicativa de baja redundancia (con contenidos heterogéneos) y/o con una función ornamental con reglas laxas. Los repertorios compartidos documentan, además, numerosos vínculos interregionales, que son corroborados mediante otras líneas de evidencia arqueológica.

Palabras clave: placas grabadas-Patagonia-repertorios-ornamentación-comunicación

\footnotetext{
*Asociación de Investigaciones Antropológicas, Consejo Nacional de Investigaciones Científicas y Técnicas, Universidad de Buenos Aires, E-mail: danae_fiore@yahoo.es

**A Asociación de Investigaciones Antropológicas, Consejo Nacional de Investigaciones Científicas y Técnicas, E-mail: agustinacevedo2009@gmail.com

*** Instituto de Investigaciones Arqueológicas y Paleontológicas del Cuaternario Pampeano, Consejo Nacional de Investigaciones Científicas y Técnicas - Facultad de Ciencias Sociales, Universidad Nacional del Centro de la Provincia de Buenos Aires, E -mail: cfavier3@gmail.com
} 
Relaciones de la Sociedad Argentina de Antropología 46 (2), julio-diciembre 2021: 629-655

\author{
DURABLE GEOMETRIES. THE CASE OF THE ENGRAVED LITHIC PLAQUES \\ FROM GOLFO SAN MATÍAS (RÍO NEGRO PROVINCE) AND THEIR CONTEXT IN \\ ARGENTINEAN PATAGONIA
}

\title{
ABSTRACT
}

This paper analyses a collection of engraved plaques from Golfo San Matías (Río Negro province) in order to assess design recurrences which might point to the presence of ornamentation rules and/or visual information coding among the hunter-gatherer peoples who produced and used them. Then, 170 plaques from Patagonia and other regions of Argentina are systematically compared using the presence of shared motif types as the main criterion. Data are assessed using a theoretical model with expectations which link design variability/standardization, ornamental laxity/structuration and informational heterogeneity/redundancy. Results show that plaques display low design standardization, which is compatible with a low redundancy communicative function (heterogeneous content) and/or with an ornamental function with lax rules. Moreover, the shared repertoires document several inter-regional links, which are verified using different lines of archaeological evidence.

Keywords: engraved plaques - Patagonia - repertoire - ornamentation - communication

\section{INTRODUCCIÓN}

El objetivo de este trabajo es presentar un conjunto de placas líticas grabadas, procedentes del Golfo San Matías (costa norte de Patagonia, provincia de Río Negro), caracterizarlas siguiendo criterios previamente desarrollados en trabajos anteriores (Acevedo 2015, 2016) y proceder a la comparación de sus morfologías, diseños y tipos de motivos contra una muestra conformada por 170 placas de la Patagonia argentina y regiones adyacentes. Dicha comparación permitirá evaluar la existencia de vínculos entre las distintas zonas de procedencia de estos artefactos, que arrojará luz sobre la circulación de objetos y/o información en el contexto de la interacción y contactos de poblaciones cazadoras-recolectoras de la Patagonia.

El golfo San Matías (en adelante GSM) posee un clima semiárido, con una temperatura media de $15^{\circ} \mathrm{C}$, precipitaciones menores a los $300 \mathrm{~mm}$ anuales y vegetación arbustiva correspondiente a la provincia de Monte (Cabrera y Willink 1980). Las investigaciones arqueológicas revelaron la existencia de ocupaciones humanas al menos desde el Holoceno medio ( $c a .6000$ años ${ }^{14} \mathrm{C} \mathrm{AP}$ ) y reconocieron dos etapas. Una primera etapa (ca. 6000 a 2000 años ${ }^{14} \mathrm{C}$ AP) que evidencia un uso intensivo de la fauna marina, particularmente peces y lobos marinos, y una segunda etapa (ca. 1500 a 400 años ${ }^{14} \mathrm{C}$ AP) en la que su uso es moderado a bajo, con una diversificación en las especies consumidas, con un aumento en la importancia de las terrestres como el guanaco y el ñandú (Favier Dubois et al. 2009a; Favier Dubois y Kokot 2011). Estos resultados se basan en información arqueofaunística y paleodietaria (isótopos estables de C y N sobre restos humanos). En la última etapa se registran además cambios tecnológicos, así como un aumento en la movilidad de los grupos y en la circulación de materias primas (Favier Dubois et al. 2009b).

Las preguntas de investigación que guían nuestro trabajo se orientan a pesquisar si existieron códigos de comunicación y/o de ornamentación, subyacentes a la producción de los diseños visuales de las placas, identificables dentro de la colección del GSM, y/o compartidos entre diversas regiones de la Patagonia. La identificación de estos potenciales códigos compartidos podría indicar la existencia de redes de comunicación visual entre poblaciones cazadoras-recolectoras, operando a escala regional y/o macro-regional. Contrariamente, la falta de evidencia de estos códigos y la identificación de elementos específicos de índole más detallada y sutil (por ej. ciertos tipos de 
motivos), compartidos en las mismas escalas abonaría la existencia de formas de comunicación más heterogéneas y menos estandarizadas, que podrían haber funcionado como mecanismos de interacción socialmente menos reglados.

Asimismo, se analizará la existencia de conexiones interregionales para evaluar si hubo predominio de contactos entre zonas próximas (esperable en interacciones frecuentes y directas) y/o entre zonas no-vecinas (esperable en interacciones a larga distancia). Los contactos hallados se contrastarán con otras líneas de evidencia (por ej. procedencia de obsidianas, cuarcitas y moluscos hallados en el GSM) que marquen vínculos en las mismas escalas para evaluar si ocurrieron entre las mismas regiones.

\section{ANTECEDENTES}

El término "placas grabadas" se utiliza para definir a un conjunto de artefactos líticos de superficies planas y espesor reducido, de formas y tamaños variados, decorados con diseños grabados (Fernández 1982). Usualmente están confeccionadas sobre rocas blandas (por ej. metamórficas de bajo grado de la serie arcillosa y sedimentarias carbonáticas) y no se conoce aún si tuvieron funciones práctico-mecánicas. Actualmente se dispone de información publicada sobre más de 180 ejemplares de placas, provenientes principalmente de Patagonia y Pampa y, en menor frecuencia, Sierras Centrales, Cuyo, NOA y NEA, asignados temporalmente al Holoceno tardío (Losada Gómez 1980; Barrientos et al. 1997; Berón 1997; Oliva 2006; Acevedo 2015; Zubimendi et al. 2016; Carden y Martínez 2014; Cassiodoro et al. 2019; Lynch et al. 2019; entre otros).

Las investigaciones sobre estos artefactos atraviesan la historia de la arqueología argentina desde sus inicios hasta el presente. Debido a limitaciones de espacio, no citaremos la totalidad de los antecedentes sobre esta temática, que pueden encontrarse analizados en Acevedo (2015). Cabe mencionar, sin embargo, que los estudios de estos materiales comienzan con Ameghino ([1880] 1947) y tienen un considerable desarrollo durante las primeras décadas del siglo XX, en las cuales autores como Verneau, Outes, Lehmann-Nitsche, Torres, Vignati y Greslebin propusieron diversas interpretaciones sobre sus potenciales funciones, sin validación empírica, en concordancia con las prácticas de la época.

Posteriormente, Bórmida, Schobinger y Losada Gómez desarrollaron estudios de índole histórico-cultural, con objetivos orientados al ordenamiento espacio-temporal de las placas y la identificación de las culturas productoras. En este marco, Menghin (1957) señaló la existencia de similitudes entre los motivos grabados en las placas y los del Estilo de grecas del arte rupestre. Esto sería respaldado posteriormente por Gradin (1973) y brindaría un marco temporal relativo (Holoceno final) dentro del cual insertar la producción de estos materiales.

Investigaciones desde marcos procesuales y postprocesuales se han enfocado en la cronología y análisis de las placas como evidencias de procesos socio-económicos regionales. Esto incluye: a) la datación de ejemplares provenientes de contextos estratigráficos de la región pampeana, en momentos del Holoceno tardío final: ca. 1100 a 400 años ${ }^{14} \mathrm{C}$ AP (Barrientos et al. 1997; Berón 1997; Oliva 2006); b) la interpretación de su uso a escala intrarregional, como señalización de identidades de grupos cazadores-recolectores en situación de competencia por espacios y recursos (Barrientos y Perez 2004; Berón 2006; Curtoni 2006); y c) a escala interregional, para la construcción de mecanismos de integración entre poblaciones dispersas para minimizar riesgos en contextos de stress ambiental (Belardi 2004; Berón 2006).

En los últimos años han resurgido las investigaciones focalizadas en los artefactos, que aportan información novedosa sobre: a) la existencia de vínculos morfológicos entre los diseños de placas provenientes de diferentes regiones (Acevedo 2015, 2016; Cassiodoro et al. 2019; Lynch et al. 2019); b) la homogeneidad técnica en los motivos grabados (Lynch et al. 2019); c) la utilización 
de materias primas líticas locales (Cassiodoro et al. 2019) y no-locales (ca. $90 \mathrm{~km}$ ) (Lynch et al. 2019); d) los tratamientos previos sobre las superficies a ser grabadas (Lynch et al. 2019); e) su vinculación con diferentes contextos de actividades domésticas y específicas (Cassiodoro et al. 2019; Lynch et al. 2019); y f) las primeras dataciones para ejemplares provenientes de Patagonia (ca. 1700 y 1900 años ${ }^{14}$ C AP) (Lynch et al. 2019).

Finalmente, otro pequeño grupo de publicaciones constituye un antecedente indirecto sobre el tema bajo estudio en este trabajo: se trata de aquellas relativas a los análisis de fragmentos de cáscara de huevo de Rheidae en Patagonia, cuyos motivos altamente geométricos han sido grabados sobre soportes transportables, pero de alta fragilidad, lo cual implica la habitual fragmentación de los diseños. Sin embargo, éstos han permitido identificar un conjunto mínimo de tipos de motivos compartidos entre varios sitios/loci de la costa norte del golfo San Matías (Fiore y Borella 2010) como en el curso inferior del río Colorado y colecciones comparativas (Carden y Martínez 2014). El estudio de estas "geometrías delicadas" o "geometrías fracturadas", como las denominaron respectivamente las/los autores, constituye un antecedente al análisis de las geometrías perdurables que encaramos en este trabajo. Como veremos a continuación, esta denominación no solo remite a la perdurabilidad de los soportes sobre los cuales están hechas, sino también a la existencia de determinados tipos de motivos que perduran en el espacio, en localidades o regiones distantes entre sí.

\section{MARCO TEÓRICO}

El arte mobiliar tiene una serie de características materiales que se vinculan con sus funciones práctico-mecánicas y sociales (Conkey 1980; d’Errico 1994; Dobres 2001; Fiore 2012, 2020; Acevedo 2015; Carden y Borges Vaz 2017). Tanto el tipo de artefacto como el corpus de imágenes producidas en/sobre el artefacto, e incluso las técnicas con que éstas fueron creadas, pueden haber operado como medios de comunicación de información de variada naturaleza (ecológica, de estatus social, identitaria, de cosmovisión, etc.), así como también pueden haber respondido a motivaciones ornamentales (Conkey 1980; d’Errico 1994; Dobres 2001; Fiore 2012, 2020; Acevedo 2015; Carden y Borges Vaz 2017).

La función ornamental de las imágenes de arte mobiliar alude a la capacidad de éstas de decorar un objeto con diseños compuestos por uno o varios motivos (unidades básicas del diseño), con ciertas características tecno-morfológicas (forma, tamaño, color, etc.), que frecuentemente no se disponen de manera azarosa, sino que están estructuradas de determinada forma en el espacio plástico del soporte (en este caso, con determinada posición, orientación, repetición en/ sobre el artefacto) (Fiore 2011). La materialidad de estos diseños, con estas características y estructuración, genera efectos estéticos sobre quienes las perciben, produciendo respuestas sensoriales, emocionales, imaginativas, de entendimiento, etc. (Heyd 2014). Si bien dichas respuestas dependen de la interacción sujeto/imagen-objeto, las pautas recurrentes en la materialidad de éstos aportan vías de acceso a la dimensión estética de la ornamentación, ya que revelan aspectos de la intencionalidad de los/las productores. Así, estas tendencias en la ornamentación pueden comunicar información acerca de la procedencia, agentes productores y/o funcionalidad social de las imágenes-objeto.

La función comunicativa visual del arte mobiliar se basa sobre la potencialidad de las imágenes para codificar, contener y transmitir información. Dicho proceso se inicia cuando los/las productores codifican información materializada en uno o varios motivos que representan a un referente externo, estructuradas de determinada forma en el espacio plástico del soporte (en este caso, en/sobre el artefacto). Así, la información contenida en dichas imágenes representativas puede ser luego decodificada, comprendida e interpretada por personas que compartan el mismo 
código visual para acceder desde el plano sintáctico al semántico, incluso en ausencia de los/las productores de las imágenes (Fiore 2011). Esta es la gran ventaja que aportan los sistemas de comunicación visual realizados sobre soportes portátiles tales como el arte mobiliar, ya que, como han demostrado numerosos arqueólogos/as, permite generar redes de comunicación a escalas espaciales amplias, incluso entre poblaciones de regiones que no necesariamente hablarían la misma lengua (Gamble 1982). Ahora bien, los diseños representativos pueden haber codificado información tanto de manera figurativa (manteniendo una relación icónica con el referente) como de manera no-figurativa (representando el referente de manera no-icónica). A ello se suma que algunas imágenes pueden haber carecido de referentes externos, es decir, haber sido diseños no-representativos: estos casos no habrían cumplido con una función comunicativa de manera explícita ni mediante un código visual estructurado tal como el arriba definido (Fiore 2011). Debido a la dificultad de distinguir arqueológicamente entre diseños representativos no-figurativos y diseños no-representativos, en este trabajo tomamos la función comunicativa como una potencialidad de la imagen-objeto de arte mobiliar, pero no aseguramos que todas ellas hayan sido producidas con esta finalidad.

Interesantemente, ambas motivaciones -comunicativa y ornamental- requieren que la producción artística esté sujeta a cierto conjunto de procedimientos que orientan tanto la percepción de las cualidades plásticas de la imagen-objeto generando efectos estéticos, como la posibilidad de decodificación e interpretación del potencial contenido informativo (especialmente en ausencia del/a productor/a), según el contexto de producción/uso del material artístico. Si bien la ornamentación puede en algunos casos prescindir de una estructuración pautada de la imagen, es habitual que dicha estructuración exista; en el caso de la comunicación, la estructuración es imprescindible para que ésta ocurra. Esto conlleva la paradoja de que tanto comunicación como ornamentación requieran códigos, lo cual genera un potencial problema de equifinalidad, especialmente cuando ambas funciones no son contrapuestas, sino potencialmente complementarias. Sin embargo, parte de esta equifinalidad puede desentrañarse. Tanto para sostener funciones comunicativas como ornamentales, la producción de objetos-imágenes de arte mobiliar implica cuatro elementos conjugados: un soporte, una o varias técnicas de producción de imágenes, un repertorio de tipos de motivos (en adelante TM) y una forma de combinarlos en cada pieza de arte mobiliar. Si bien los cuatro elementos pueden ser más o menos activos tanto en la comunicación como en la ornamentación, la existencia de un repertorio de TM compartidos es el indicador más directo para evaluar la existencia de circulación de información a escala interregional (Conkey 1980; Belardi 2004; Fiore 2006; Fiore y Borella 2010; Carden y Martínez 2014; Acevedo 2015). Por esta razón nos concentraremos en este indicador como eje de nuestro análisis.

En cuanto a los TM, en primer lugar, la creación de un repertorio implica el uso de un rango limitado de tipos, ya que esto permite la función comunicativa del arte. En segundo lugar, cada TM requerirá una cierta estandarización que permita una interpretación visual no ambigua (si es que comunica información) y/o un rango de opciones de diseño que permitan una apreciación estética orientada (si es que está diseñada para generar efectos ornamentales) dentro de un marco cultural de reglas de interpretación/apreciación.

Finalmente, el arte mobiliar puede implicar el uso de un solo TM (de forma única o repitiéndolo dos o más veces), pero también la combinación de varios TM en una misma pieza. Presentamos, entonces, un modelo teórico que combina dos variables para evaluar la variabilidad y recurrencias en los diseños bajo estudio y desentrañar sus patrones ornamentales y comunicativos: 1) tamaño del repertorio (cantidad de TM); 2) estructuración de los diseños (restringido aquí a las combinaciones de TM). La combinatoria de estas variables permite modelar cuatro situaciones: a) repertorio acotado y con baja estructuración; b) repertorio acotado y altamente estructurado; c) repertorio amplio y con baja estructuración; d) repertorio amplio y altamente estructurado. De éstas, la situación "a" es la que implica una mínima complejidad, mientras que la situación "d" implica 
una máxima complejidad tanto en la función ornamental como en la informativa. Contrariamente, las situaciones "b" y "c", que combinan estados de las variables opuestos entre sí, son las más relevantes para explorar y evaluar potenciales diferencias sutiles entre ornamentación y comunicación. En el caso "b", el uso de un repertorio acotado de TM, combinados siempre de la misma manera, implica una muy alta estandarización compositiva. Dicha estandarización respondería a una función ornamental sumamente regulada y/o a una función comunicativa de alta redundancia informativa, comunicando mensajes homogéneos (de contenido igual o muy similar), orientando efectivamente la interpretación de su significado y restringiendo la posibilidad de ambigüedad y/o polisemia debido al alto grado de codificación (Hartley 1992; Carden 2004; Guichón 2018). El caso opuesto, "c", sería el de un repertorio amplio con varios TM, con una baja repetición de TM entre artefactos y/o con combinaciones de TM casi siempre distintas, que implicarían una muy baja estandarización compositiva. Esta respondería a una producción que no se habría apegado a reglas ornamentales rígidas y/o que habría respondido a una función comunicativa de baja redundancia informativa, que: 1) o bien comunicaría mensajes heterogéneos (de contenido diverso) cuya decodificación requeriría de un manejo sutil de un complejo código visual compartido, porque el contenido informativo de cada imagen sería distinto; 2) o bien funcionaría con un bajo grado de codificación de información, dando lugar a la ambigüedad y la polisemia. Nuestra investigación se centrará en aplicar estos conceptos al estudio de las placas del GSM, para luego compararlas con las de otros sitios de Patagonia, Pampa y Sierras Centrales.

\section{METODOLOGÍA}

Nuestro método de trabajo se organizó en dos etapas. La primera implicó la observación de las piezas y el registro de variables en una base de datos relacional de escalas múltiples. A escala del artefacto se registraron catorce variables, incluyendo: número de artefacto; pieza entera o fragmentada; presencia/ausencia de remontaje de fragmentos; forma general de la pieza; largo máximo (en centímetros); ancho máximo (en centímetros); espesor máximo (en centímetros); materia prima; presencia/ausencia de pulido para formatización; presencia/ausencia de forma de suspensión; técnica de producción de suspensión; técnica/s decorativa/s; $\mathrm{N}$ de porciones decoradas en la pieza; cuáles son las porciones decoradas en la pieza. A escala de porción del artefacto: número de porción; tipo de porción (cara-anverso, cara-reverso, lateral); tipo de estructuración del diseño decorativo en la porción del artefacto. A escala de motivo: número de registro de cada motivo decorativo; ubicación en porción del artefacto; clasificación del motivo según su tipo; posición; orientación; técnica de producción. La definición de motivo utilizada remite a toda expresión gráfica resultante del uso de uno o varios elementos decorativos básicos (por ej. líneas, puntos, figuras) -empleados de manera única, reiterada y/o combinada-, ejecutada mediante un trazo aparentemente unitario y/o mediante trazos discretos con una proximidad espacial notoria entre sí que se unen para formar una sola entidad visual mayor (Gradin 1978; Hernández Llosas 1985; Aschero 1988). Por su parte, los tipos de motivos refieren a un conjunto recurrente de atributos morfológicos que permiten la clasificación de varios casos de motivos en una misma categoría de diseño, la cual es morfológicamente distinta a otras categorías (Hernández Llosas 1985; Aschero 1988; Fiore 2011).

Este diseño de base de datos permite registrar información para las distintas escalas (artefacto, porción, motivo), relacionarlas entre sí y cuantificar el $\mathrm{N}$ total de motivos (NM), el $\mathrm{N}$ de tipos de motivos (NTM) y el N de casos de cada tipo por pieza y para la colección completa (Fiore 2009, 2012; Acevedo 2015). Se utilizó el índice de variabilidad (NTM/NM), que cuantifica cuánto se repiten -o no- los TM respecto del $\mathrm{N}$ de motivos dentro de cada pieza, para evaluar la variabilidad interna del diseño (Fiore 2012). Este índice brinda resultados iguales o menores a 
1. El valor 1 expresa la máxima variabilidad de TM por NM y cuanto menor el número, menor variabilidad. Al tratarse de una ratio de tipos/motivos, sirve para cuantificar datos de artefactos enteros o fragmentos, aunque es sensible a muestras pequeñas.

Los TM se identificaron tomando como referencia el repertorio ya desarrollado para Patagonia y regiones adyacentes (Acevedo 2015, 2016). Esta información se utilizó también para identificar las clases de estructuración de motivos (a escala de cada cara del artefacto):

1) estructuración clase I: decoración subdividida en cuadrantes horizontales, uno sobre el otro, separados por una línea;

2) estructuración clase II: decoración subdividida en cuadrantes verticales, uno al lado del otro, separados por una línea;

3) estructuración clase III: combinación de las clases I y II, en la que la decoración está subdividida en dos mitades - una mitad está subdividida en cuadrantes verticales y la otra mitad está subdividida en cuadrantes horizontales- todos ellos separados por líneas;

4) estructuración clase IV: decoración dispuesta de manera homogénea sobre la porción del artefacto, sin ninguna subdivisión.

La segunda etapa de la investigación consistió en efectuar una comparación de la colección bajo estudio con muestras provenientes de otras regiones -Patagonia, Pampa y Sierras Centrales- utilizando como indicador la presencia de TM compartidos. Para este fin se utilizó una base de datos compuesta por 170 placas: 157 relevadas a partir de trabajos previos (publicados entre 1880 y 2010) $)^{1}$ y 13 relevadas en colecciones de tres museos (Museo Etnográfico "Juan B. Ambrosetti" de la Ciudad de Buenos Aires, Museo de La Plata y Museo de Antropología de la Universidad de Córdoba; para más detalle de la conformación de la base de datos ver Acevedo 2012, 2015).

\section{CASO DE ESTUDIO}

Las nueve placas analizadas en este trabajo proceden de tres localidades arqueológicas de la costa del GSM: cuatro de ellas fueron halladas durante los trabajos arqueológicos desarrollados en Bajo de la Quinta y una en Punta Pórfido; y cuatro proceden de colecciones privadas - dos halladas en San Antonio Oeste y dos en Saco Viejo- (figura 1; tabla 1).

Las cuatro placas de Bajo de la Quinta provienen del locus La Noria. Allí asoman numerosos concheros con cerámica en los que se obtuvieron tres edades sobre carbón entre $c a .450$ y 942 años ${ }^{14} \mathrm{C}$ AP y una sobre valvas de mitílidos de $c a .1070$ años ${ }^{14} \mathrm{C}$ AP (Favier Dubois et al. 2009a; Favier Dubois y Kokot 2011). La placa de Punta Pórfido se halló próxima al sondeo excavado en el sector, fechado sobre valvas de mitílidos en $c a$. 980 años ${ }^{14} \mathrm{C} \mathrm{AP}$, con presencia de cerámica en superficie (Borella et al. 2015).

Respecto a las placas procedentes de colecciones radicadas en San Antonio Oeste: Saco Viejo es una localidad arqueológica cercana a la ciudad, muy visitada por aficionados y muy rica en hallazgos arqueológicos de momentos tardíos (incluso algunos del contacto hispano-indígena). En ella hemos obtenido fechados entre ca. 662 y 417 años ${ }^{14} \mathrm{C} \mathrm{AP}$ y, en la periferia del lugar, dataciones de hasta ca. 2100 años ${ }^{14}$ C AP (Favier Dubois 2013). Por otro lado, la localidad San Antonio Oeste ocupa un área muy amplia que posee variada cronología, por lo que allí es más difícil establecer un contexto temporal sin datos precisos de procedencia. Estas dos últimas localidades se destacan como lugares o nodos de circulación principales en el GSM y son las que muestran mayor cantidad y variedad de ítems arqueológicos procedentes de otras regiones (por ej. Patagonia, Pampa y Sierras Centrales; Favier Dubois et al. 2009a, 2009b). 


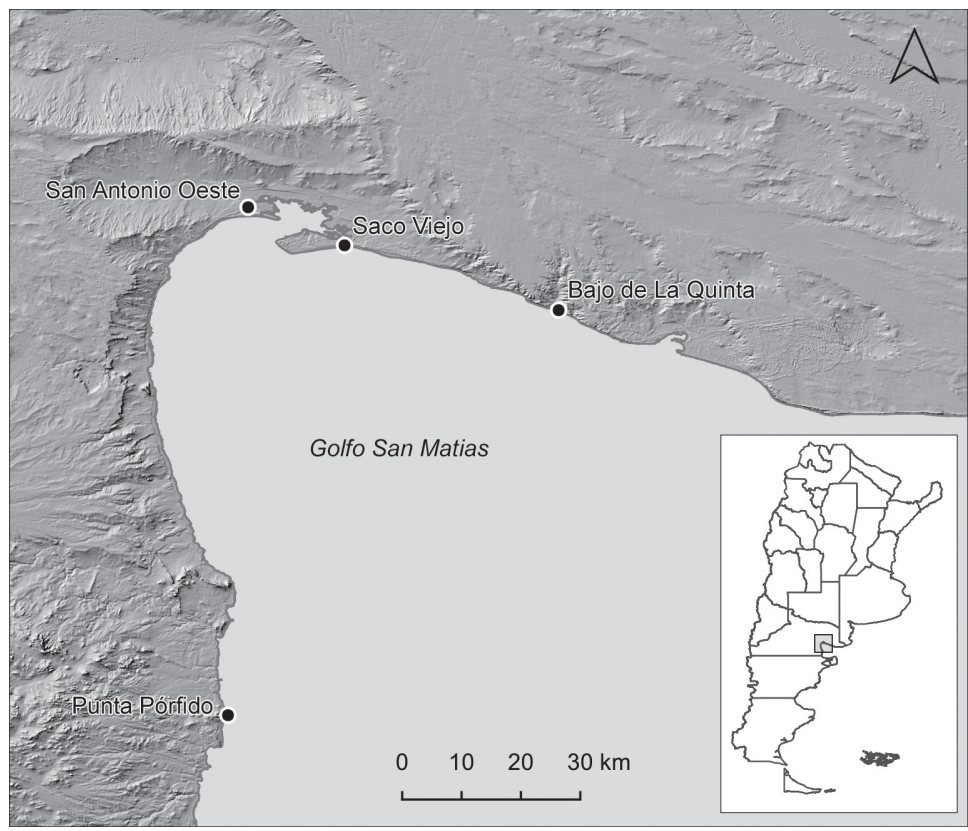

Figura 1. Localidades de procedencia de las placas grabadas del GSM

Tabla 1. Contextos de proveniencia de las placas grabadas del GSM

\begin{tabular}{|c|c|c|c|c|c|}
\hline $\operatorname{Loc}^{\mathbf{a}}$ & Artef $^{b}$ & Locus & Proveniencia & Contexto & Referencia \\
\hline \multirow{4}{*}{ BQ } & 2 & La Noria GPS 25 & Superficie & $\begin{array}{l}\text { - Concheros con cerámica } \\
\text { - Tardío }\end{array}$ & \multirow{4}{*}{$\begin{array}{l}\text { Favier Dubois et } \\
\text { al. 2009a; Favier } \\
\text { Dubois y Kokot } \\
2011\end{array}$} \\
\hline & 3 & La Noria Marca 014 & Superficie & $\begin{array}{l}\text { - Concheros con cerámica } \\
\text { - Tardío }\end{array}$ & \\
\hline & 4 & La Noria Marca 013 & Superficie & $\begin{array}{l}\text { - Concheros con cerámica } \\
\text { - Tardío }\end{array}$ & \\
\hline & 5 & La Noria Marca 013 & Superficie & $\begin{array}{l}\text { - Concheros con cerámica } \\
\text { - Tardío }\end{array}$ & \\
\hline PP & 8 & 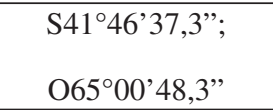 & Superficie & $\begin{array}{l}\text { - Valvas y cerámica } \\
\text { - Tardío }\end{array}$ & $\begin{array}{l}\text { Borella et al. } \\
2015\end{array}$ \\
\hline \multirow[t]{2}{*}{ SV } & 6 & - & $\begin{array}{l}\text { Colección Betty } \\
\text { Díaz (SAO) }\end{array}$ & - Tardío & \multirow{2}{*}{$\begin{array}{l}\text { Favier Dubois } \\
2013\end{array}$} \\
\hline & 7 & - & $\begin{array}{l}\text { Colección Betty } \\
\text { Díaz (SAO) }\end{array}$ & - Tardío & \\
\hline \multirow[t]{2}{*}{ SAO } & 1 & - & $\begin{array}{l}\text { Colección Maite } \\
\text { Narvarte y Raúl } \\
\text { González (SAO) } \\
\end{array}$ & - & - \\
\hline & 9 & - & $\begin{array}{l}\text { Colección Luis } \\
\text { Giuliani (SAO) }\end{array}$ & - & - \\
\hline
\end{tabular}

${ }^{\text {a }} \mathrm{BQ}=$ Bajo de la Quinta; PP = Punta Pórfido; SV = Saco Viejo; SAO = San Antonio Oeste.

${ }^{\mathrm{b}}$ Número de artefacto 
Danae Fiore y otros - Geometrías PerduRables. El caso de las Placas grabadas líticas del Golfo ...

\section{RESULTADOS}

Arte mobiliar en pequeña escala: análisis de cada artefacto y de la colección bajo estudio

La colección se compone de nueve artefactos, tres de ellos enteros y el resto fragmentos (tabla 2; figura 2 y 3). A partir de los artefactos enteros, es posible notar que el rango de tamaños es variable, ya que los largos van desde $11,7 \mathrm{~cm}$ a $5,6 \mathrm{~cm}$. Contrariamente, los espesores tienen medidas comparativamente homogéneas, que rondan $1 \mathrm{~cm}$ en promedio, lo cual sugiere una cierta estandarización en la selección de soportes líticos poco espesos, quizá más adecuados para su manipulación y transporte. Las formas generales -en artefactos enteros y fragmentos- muestran variabilidad: rectilíneas (subtrapezoidal, subrectangular) y curvilíneas (circular, subelíptica). Seis de las nueve placas presentan rastros de posible pulido, que podría haber sido resultado de pulimento intencional, por manipulación o, en algunos casos (por ej. Bajo de la Quinta) por abrasión eólica postdepositacional. Ninguno de los artefactos tiene filo natural ni formatizado, ni puntas destacadas, lo cual reduce sus potenciales funciones práctico-mecánicas. Solamente uno de ellos (artefacto $\mathrm{n}^{\circ} 1$ ) tiene tres perforaciones (en los extremos superior, inferior izquierdo y derecho; figura 2a), lo cual sugiere que habría sido diseñado para ser suspendido o sujetado en alguna estructura (por ej. poste de toldo) o bien sobre el cuerpo (por ej. en forma de pendiente o similar).

Las porciones decoradas en cada pieza varían desde una hasta cinco: debido a la fragmentación de la mayoría de las piezas de la muestra, no es posible evaluar si el número de porciones decoradas covaría con el tamaño y/o con la morfología de aquellas. Sin embargo, resulta interesante notar que hay fragmentos de tamaño pequeño, con longitudes de $4 \mathrm{~cm}$ aproximadamente, que tienen dos o tres porciones decoradas, al igual que fragmentos más grandes, de $7 \mathrm{~cm}$ y $8 \mathrm{~cm}$ de largo aproximadamente, que tienen la misma cantidad de porciones decoradas, lo cual permite sugerir que la elección de cuántas porciones decorar en una pieza no habría sido directamente dependiente de su tamaño, aunque éste pudiera influir (por ej. la pieza más grande, que tiene casi $12 \mathrm{~cm}$ de largo, cuenta con cinco porciones decoradas).

En cuanto a la clase de estructuración de los diseños, la mayoría de las piezas $(n=6)$ tienen un único tipo de estructuración, de clase IV, en todas sus porciones decoradas: ello indica claramente una intencionalidad de mantener homogeneidad intraartefacto en la estructura general del diseño artístico. Las tres piezas restantes tienen dos porciones decoradas, con distintos tipos de estructuración de diseño: clase I combinada con clase IV, o clase I combinada con clase II.

Tabla 2. Características generales de la muestra

\begin{tabular}{|c|c|c|c|c|c|c|c|c|c|c|}
\hline $\mathrm{Art}^{\mathrm{a}}$ & Loc $^{a}$ & Est $^{\mathrm{a}}$ & Forma & $\operatorname{Rem}^{\mathrm{a}}$ & $\mathbf{P u l}^{\mathbf{a}}$ & Larg $^{\mathrm{a}}$ & Anch $^{a}$ & Esp $^{a}$ & $\mathbf{P D}^{\mathbf{a}}$ & Estr $^{\mathbf{a}}$ \\
\hline 1 & $\mathrm{SAO}$ & ent $^{\mathrm{b}}$ & subtrap $^{b}$ & si & si & 11,7 & 6,8 & 0,54 & 5 & IV \\
\hline 2 & BQ & frag $^{\mathrm{b}}$ & indet $^{\mathrm{b}}$ & no & si & 3,74 & 2,44 & 1,16 & 3 & IV \\
\hline 3 & BQ & ent & circular & no & si & 5,6 & 5,42 & 0,8 & 2 & IV \\
\hline 4 & BQ & frag & indet & no & si & 3,6 & 3,96 & 1,42 & 2 & $\mathrm{I}+\mathrm{IV}$ \\
\hline 5 & BQ & ent & subelip $^{\mathrm{b}}$ & no & si & 9,5 & 4,2 & 1,28 & 2 & $\mathrm{I}+\mathrm{IV}$ \\
\hline 6 & SV & frag & indet & no & indet & 7,7 & 4,2 & 1 & 2 & $\mathrm{I}+\mathrm{II}$ \\
\hline 7 & SV & frag & subrect $^{\mathrm{b}}$ & no & indet & 7 & 3,9 & 0,38 & 3 & IV \\
\hline 8 & PP & frag & indet & no & indet & 5,4 & 7,5 & 0,8 & 2 & IV \\
\hline 9 & $\mathrm{SAO}$ & frag & subelip & no & si & 4,3 & 3,1 & 1,1 & 1 & IV \\
\hline
\end{tabular}

${ }^{\text {a }}$ Art $=\mathrm{n}^{\circ}$ de artefacto Loc $=$ Localidad $(\mathrm{BQ}=$ Bajo de la Quinta $; \mathrm{PP}=$ Punta Pórfido SV = Saco Viejo; SAO = San Antonio Oeste); Est = Estado; Rem = Remontaje Pul = Pulido Larg = Largo $(\mathrm{cm}) ;$ Anch = Ancho $(\mathrm{cm}) ;$ Esp = Espesor $(\mathrm{cm}) ; \mathrm{PD}=$ Porciones decoradas; Estr = Estructuración.

${ }^{\mathrm{b}}$ ent $=$ entera; frag $=$ fragmentada; subtrap $=$ subtrapezoidal; subelip $=$ subeliptica; subrect $=$ subrectangular; indet $=$ indeterminable. 
En cuanto a las imágenes que decoran estas placas, se trata de diseños altamente geométricos, principalmente con motivos rectilíneos de estructura interna tanto ortogonal como diagonal y, en menos casos, de diseños curvilíneos de trazos curvos y sinuosos. Esto resulta concordante con los repertorios ya conocidos para las placas de Pampa, Patagonia y regiones vecinas (Lehmann-Nistche 1909; Outes 1916; Bórmida 1952; Losada Gómez 1980; Curtoni 2006; Acevedo 2015; entre otros). Respecto a los TM que componen el repertorio de imágenes, hemos identificado un total de 48 TM, que se organizan en siete clases. De éstas, dos incluyen los tipos más frecuentes: tipos rectilíneos (RL) y tipos de figuras rectilíneas combinadas con motivos rectilíneos (FG RL-RL). El resto de las clases incluyen tipos muy poco frecuentes: tipos de figuras rectilíneas (FG RL), tipos curvilíneos-rectilíneos (CL-RL), tipos de figuras rectilíneas peiniformes (FG RL-PNF), tipos puntiformes-rectilíneos (PTF-RL), y otros tipos (O) (tabla 3).

Tabla 3. Clases de motivos registradas en cada artefacto

\begin{tabular}{|c|c|c|c|c|c|c|c|c|c|}
\hline $\mathbf{A r t}^{\mathbf{a}}$ & $\mathbf{C L}-\mathbf{R L}^{\mathbf{a}}$ & $\mathbf{F G} \mathbf{R L}^{\mathbf{a}}$ & $\begin{array}{c}\mathbf{F G} \\
\mathbf{R L}-\mathbf{P N F}\end{array}$ & $\begin{array}{c}\mathbf{F G} \\
\mathbf{R L}^{2}-\mathbf{R L}^{\mathbf{a}}\end{array}$ & ${\mathbf{P T F}-R L^{\mathbf{a}}}$ & $\mathbf{R L}^{\mathbf{a}}$ & $\mathbf{O}^{\mathbf{a}}$ & $\mathbf{N M}^{\mathbf{a}}$ & $\mathbf{N T M}^{\mathbf{a}}$ \\
\hline $\mathbf{1}$ & - & 2 & - & 17 & - & 26 & - & 45 & 27 \\
\hline $\mathbf{2}$ & - & - & - & - & - & 3 & - & 3 & 2 \\
\hline $\mathbf{3}$ & - & - & - & - & - & 2 & - & 2 & 2 \\
\hline $\mathbf{4}$ & - & - & - & - & - & 3 & - & 3 & 3 \\
\hline $\mathbf{5}$ & - & - & - & 3 & - & 8 & - & 11 & 7 \\
\hline $\mathbf{6}$ & 1 & - & 1 & 2 & 1 & 8 & 1 & 14 & 14 \\
\hline $\mathbf{7}$ & - & - & - & - & - & 3 & - & 3 & 3 \\
\hline $\mathbf{8}$ & - & - & - & 3 & - & 5 & - & 8 & 7 \\
\hline $\mathbf{9}$ & - & - & - & - & - & 2 & - & 2 & 1 \\
\hline Total & $\mathbf{1}$ & $\mathbf{2}$ & $\mathbf{1}$ & $\mathbf{2 5}$ & $\mathbf{1}$ & $\mathbf{6 0}$ & $\mathbf{1}$ & $\mathbf{9 1}$ & $\mathbf{4 8}$ \\
\hline
\end{tabular}

${ }^{\mathrm{a}}$ Art $=$ Artefacto $; \mathrm{FG}=$ Figuras $; \mathrm{CL}=$ Curvilíneos $; \mathrm{RL}=$ Rectilíneos $; \mathrm{PNF}=$ Peiniformes $; \mathrm{PTF}=$ Puntiformes $; \mathrm{O}=\mathrm{Otros}$; $\mathrm{NM}=\mathrm{N}$ de motivos $; \mathrm{NTM}=\mathrm{N}$ de tipos de motivos.

A continuación, presentamos una breve descripción de los diseños decorativos de cada artefacto (figura 2 y 3), dando cuenta de los TM que los componen, de su estructuración en el espacio plástico del soporte y de sus características técnicas, para luego efectuar una evaluación comparativa de la colección.

1) Artefacto $n^{\circ} 1$ (figura 2a): ejemplar producido sobre pizarra, con potenciales rastros de formatización mediante pulido. Presenta decoración en ambas caras (anverso y reverso), ambos laterales (izquierdo y derecho) y en el borde superior. En anverso y reverso la decoración presenta estructuración de clase IV (homogénea). En ambos laterales la decoración está limitada espacialmente en su distribución a los sectores inferiores del artefacto (cercanos a la base) y es también de clase IV. En el borde superior (actualmente interrumpido por una fractura y remontado) la decoración está distribuida por toda su extensión. Todos los motivos han sido ejecutados mediante la técnica de grabado inciso. Este artefacto presenta el diseño más complejo de toda la muestra: consta de 45 motivos clasificados en 27 tipos, que se disponen de forma más abigarrada en el anverso (21 motivos y 15 tipos) que en el reverso (20 motivos y 14 tipos). El anverso presenta múltiples reticulados oblicuos, un reticulado ortogonal en franja, una guarda de triángulos rellenos con reticulado oblicuo, tableros simples y rellenos con reticulado oblicuo, rectángulos con bordes peiniformes hacia el exterior y motivos linea- 
les rectilíneos. En el reverso se destacan cinco guardas de rombos rellenos con reticulado y adosados por líneas rectas paralelas, un rombo relleno con reticulado y dos rombos adosados, varios reticulados oblicuos dispuestos en franjas y guardas, dos almenados dobles con reticulado exterior, un zigzag doble y varios motivos lineales rectilíneos. Por su parte, el lateral izquierdo, lateral derecho y borde superior, fueron decorados con dos tipos similares: guiones paralelos y guiones paralelos múltiples.

2) Artefacto $n^{\circ} 2$ (figura $2 b$ ): ejemplar producido sobre roca carbonática, con potenciales rastros de formatización mediante pulido. Presenta decoración en ambas caras (anverso y reverso) y en el borde inferior, todas con estructuración de clase IV. Todos los motivos han sido ejecutados mediante la técnica de grabado inciso. El repertorio decorativo en este artefacto es muy acotado, consta solamente de tres motivos, clasificados en dos tipos: en el reverso se observan líneas rectas paralelas rellenas con líneas rectas perpendiculares transversales, mientras que en el anverso y en el borde inferior se registran reticulados oblicuos.

3) Artefacto $n^{\circ} 3$ (figura $2 c$ ): ejemplar producido sobre una roca carbonática, con potenciales rastros de formatización mediante pulido. Presenta decoración en ambas caras (anverso y reverso), con una estructuración de clase IV. Todos los motivos han sido ejecutados mediante la técnica de grabado inciso. En este artefacto los motivos decorativos son solamente dos, correspondientes a dos tipos distintos: reticulado ortogonal en el anverso y líneas rectas entrecruzadas ortogonalmente en el reverso.

4) Artefacto $n^{\circ} 4$ (figura $2 d$ ): ejemplar producido sobre roca carbonática, con potenciales rastros de formatización mediante pulido. Presenta decoración en ambas caras (anverso y reverso), con estructuración de clase IV en el anverso y clase I en el reverso. Todos los motivos que componen el diseño del artefacto han sido ejecutados mediante la técnica de grabado inciso. Los motivos registrados en el artefacto son tres, correspondientes a tres tipos distintos: en el anverso se observa una guarda de reticulado oblicuo; en el reverso, una línea recta con líneas rectas paralelas múltiples perpendiculares y líneas rectas paralelas múltiples.

5) Artefacto $n^{\circ} 5$ (figura 3a): ejemplar producido sobre roca carbonática, con potenciales rastros de formatización mediante pulido. Presenta decoración en ambas caras (anverso y reverso). En el anverso la decoración presenta una estructuración de clase I (subdividida en tres cuadrantes horizontales uno sobre el otro, separados por líneas rectas). En el reverso la decoración presenta una estructuración de clase IV (homogénea). Todos los motivos han sido ejecutados mediante la técnica de grabado inciso. El artefacto está decorado con un total de once motivos, clasificados en siete tipos. El anverso presenta: líneas rectas; líneas rectas paralelas múltiples; líneas rectas entrecruzadas irregularmente; cuadrado con grilla ortogonal interna; escaleriforme cerrado relleno con reticulado oblicuo y laberinto cerrado relleno con reticulado oblicuo adosado a rombo relleno con reticulado oblicuo. Contrariamente, el reverso presenta solamente un motivo, conformado por líneas rectas entrecruzadas irregularmente.

6) Artefacto $n^{\circ} 6$ (figura $3 b$ ): ejemplar producido sobre roca carbonática. No se han observado huellas asignables a formatización. Presenta decoración en ambas caras (anverso y reverso). En el anverso la decoración presenta una estructuración de clase I (subdividida en dos cuadrantes horizontales); en el reverso la decoración presenta una estructuración de clase II (subdividida en dos cuadrantes verticales). La mayor parte de los motivos son de trazo lineal y han sido ejecutados con la técnica de grabado inciso. Este artefacto presenta también motivos y elementos puntiformes, que aparentemente han sido ejecutados mediante horadación y percusión indirecta. ${ }^{2}$ Los motivos observados son catorce, correspondientes a catorce tipos, es decir que el diseño tiene una alta variabilidad, ya que los TM no se repiten. Cada cara del artefacto registra siete motivos. En el anverso se registran: líneas rectas paralelas; líneas rectas paralelas rellenas con líneas rectas oblicuas; guiones paralelos múltiples; rombo relleno con reticulado oblicuo; guarda de rombos rellenos con líneas rectas oblicuas; zigzags paralelos 
y zigzags paralelos múltiples adosados a líneas rectas paralelas rellenas con líneas rectas perpendiculares. En el reverso se registran: línea recta; línea recta con líneas rectas paralelas transversales; líneas rectas paralelas múltiples con guiones perpendiculares adosados a línea curva; serie de puntos; línea $\mathrm{T}$ puntiforme; triangulo relleno con líneas rectas horizontales y puntos exteriores adosado a línea $\mathrm{V}$ rellena con líneas rectas oblicuas y zigzag.

7) Artefacto $n^{\circ} 7$ (figura 3c): ejemplar producido sobre una pizarra. No se han observado huellas asignables a formatización. Presenta decoración en ambas caras (anverso y reverso) y en el lateral izquierdo. En anverso y reverso la decoración tiene una estructuración clase IV, mientras que en el lateral izquierdo la decoración está concentrada en la parte superior del lateral, pero es también de clase IV. Todos los motivos han sido ejecutados mediante la técnica de grabado inciso. Los motivos observados en el artefacto son tres y pertenecen a tres tipos distintos: en el anverso se registran líneas rectas entrecruzadas irregularmente y ortogonalmente; en el reverso se registran líneas rectas paralelas rellenas con líneas rectas oblicuas; y en el lateral izquierdo se registran guiones paralelos múltiples.

8) Artefacto $n^{\circ} 8$ (figura 3e): ejemplar producido sobre roca carbonática. No se han observado huellas asignables a formatización. Presenta decoración en ambas caras (anverso y reverso), con una estructuración de clase IV. Todos los motivos que componen el diseño del artefacto han sido ejecutados mediante la técnica de grabado inciso. El diseño decorativo de este artefacto está compuesto por un total de ocho motivos, clasificados en siete tipos. En el anverso presenta guarda de reticulado oblicuo; clepsidra rellena con reticulado oblicuo; rectángulo relleno con reticulado oblicuo y un rombo relleno con reticulado oblicuo y rombo interior negativo. En el reverso presenta línea recta, peiniforme, guarda de reticulado oblicuo y reticulado oblicuo irregular.

9) Artefacto $n^{\circ} 9$ (figura $3 d$ ): ejemplar producido sobre roca carbonática, con potenciales rastros de formatización mediante pulido. Presenta decoración en una sola cara, con una estructuración de clase IV. Todos los motivos han sido ejecutados mediante la técnica de grabado inciso. Los motivos decorativos son solamente dos, ambos pertenecientes al mismo tipo: guarda de reticulado oblicuo.
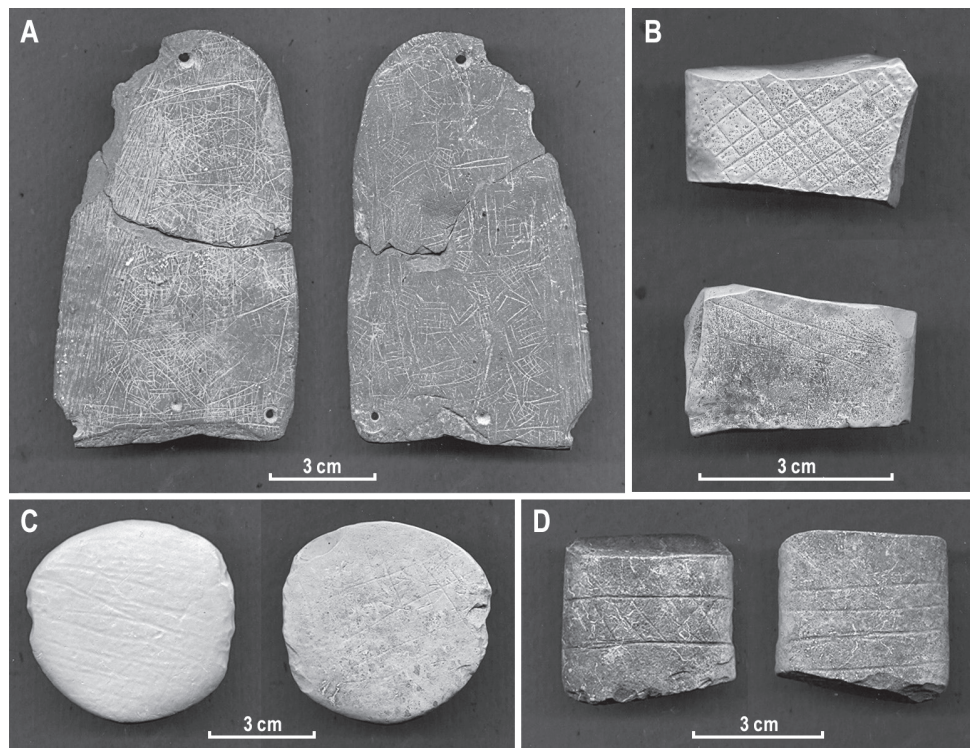

Figura 2. Placas grabadas del GSM: (a) Artefacto $n^{\circ} 1$; (b) Artefacto ${ }^{\circ} 2$; (c) Artefacto $n^{\circ} 3$; (d) Artefacto ${ }^{\circ} 4$ 

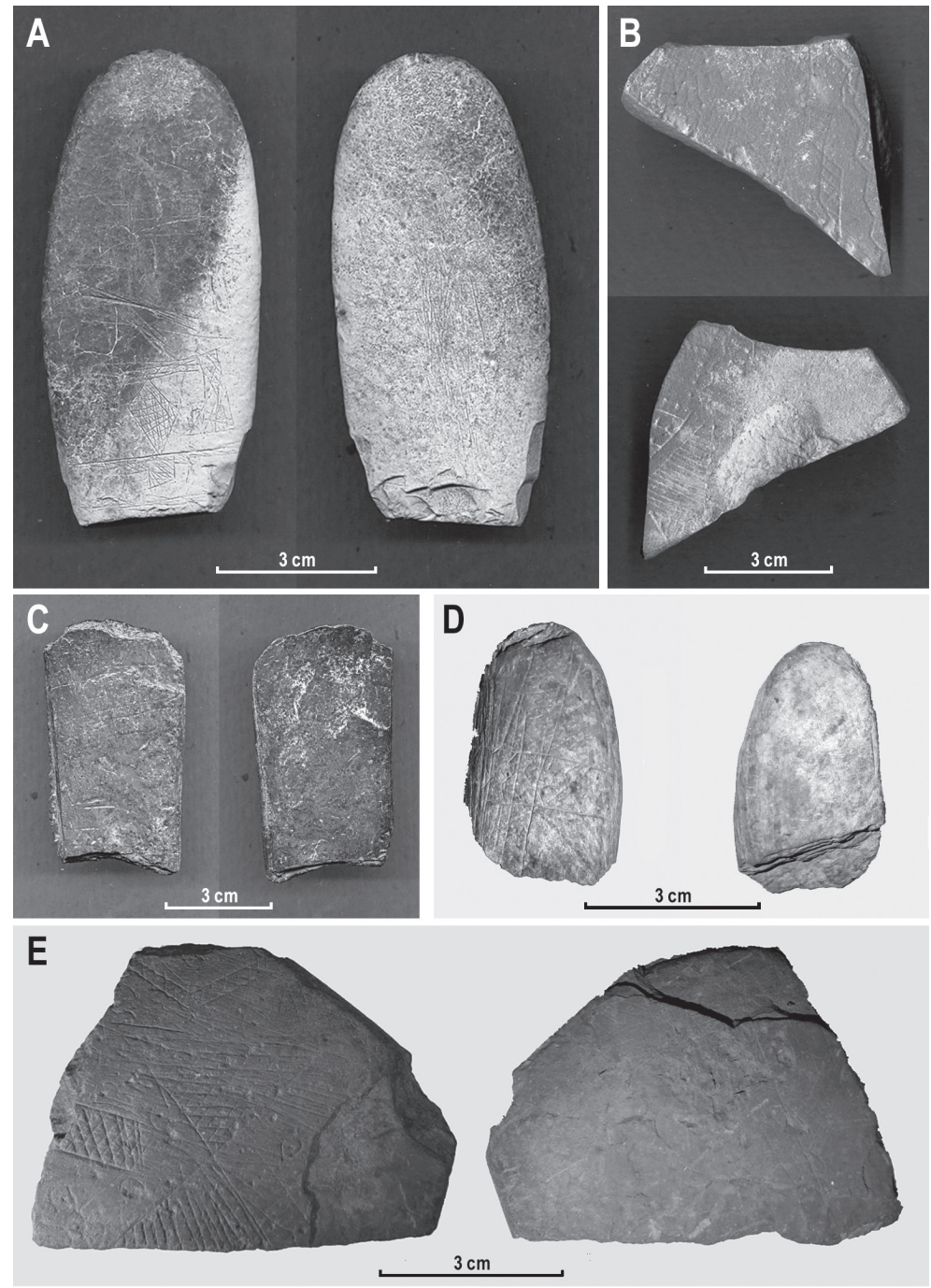

Figura 3. Placas grabadas del GSM: (a) Artefacto ${ }^{\circ} 5$; (b) Artefacto ${ }^{\circ} 6$; (c) Artefacto ${ }^{\circ} 7$; (d) Artefacto ${ }^{\circ} 9$; (e) Artefacto $n^{\circ} 8$

Como resultado del análisis de la muestra de nueve placas, se desprende que el repertorio de TM decorativos suma un total de 48 tipos (tabla 4). Para evaluar el comportamiento de este repertorio dentro de la muestra, se aplicó el índice de variabilidad (NTM/NM), para evaluar la variedad interna del diseño decorativo en cada artefacto Así, resulta evidente que hay artefactos que tienen muy bajo número de motivos pero el máximo índice de variabilidad (por ej. artefactos $\mathrm{n}^{\circ} 2,3$ y 7). Este índice es también el máximo en el artefacto $\mathrm{n}^{\circ} 6$, y muy alto en el artefacto $\mathrm{n}^{\circ} 8$, pero con un $\mathrm{N}$ de motivos comparativamente mayores, lo cual refuerza la idea de que existió una intencionalidad en la búsqueda de variabilidad interna a sus diseños decorativos. En ninguna pieza el índice es bajo. Como tendencia general, las prácticas de producción artística se orientaban a no repetir TM en cada placa (tabla 4). 
Relaciones de la Sociedad Argentina de Antropología 46 (2), julio-diciembre 2021: 629-655

Tabla 4. Frecuencias de motivos, tipos de motivos e índice de variabilidad NM/NTM

\begin{tabular}{|c|c|c|c|c|c|c|c|c|c|c|}
\hline \multirow{2}{*}{ Tipos de motivos } & \multicolumn{7}{|c|}{ Artefacto $\mathbf{n}^{\circ}$} & \multirow{2}{*}{ Total } \\
\cline { 2 - 12 } & $\mathbf{1}$ & $\mathbf{2}$ & $\mathbf{3}$ & $\mathbf{4}$ & $\mathbf{5}$ & $\mathbf{6}$ & $\mathbf{7}$ & $\mathbf{8}$ & $\mathbf{9}$ & \\
\hline Total de motivos (NM) & 45 & 3 & 2 & 3 & 11 & 14 & 3 & 8 & 2 & $\mathbf{9 1}$ \\
\hline $\begin{array}{c}\text { Total de tipos de motivos } \\
\text { (NTM) }\end{array}$ & 27 & 2 & 2 & 3 & 7 & 14 & 3 & 7 & 1 & $\mathbf{4 8}$ \\
\hline $\begin{array}{c}\text { Indice de variabilidad } \\
\text { NM/NTM }\end{array}$ & $\mathbf{0 , 6}$ & $\mathbf{0 , 6}$ & $\mathbf{1}$ & $\mathbf{1}$ & $\mathbf{0 , 6}$ & $\mathbf{1}$ & $\mathbf{1}$ & $\mathbf{0 , 9}$ & $\mathbf{0 , 5}$ & - \\
\hline
\end{tabular}

La evaluación de semejanzas y diferencias entre las nueve placas permite generar resultados relativos a la presencia de reglas de composición visual y/o de información visual compartida entre éstas. De los 48 TM que componen el repertorio, 31 son tipos únicos: aparecen en una sola pieza y no se repiten ni dentro de ésta, ni tampoco en los restantes artefactos de la muestra. Esto denota una alta variabilidad y una baja recurrencia en los diseños, lo cual sugiere que, si bien todos comparten un alto geometrismo lineal y frecuente uso de los ángulos rectos y agudos, se trataría de producciones visuales orientadas por la creatividad individual, más que por reglas de composición efectivamente estructurantes de las imágenes. Los diecisiete tipos restantes muestran algún tipo de repetición (tabla 5). En primer lugar, seis tipos se repiten a escala intraartefacto, consistiendo en casos con dos, tres o cuatro motivos del mismo tipo dentro de una misma pieza (tabla 5): éstos implican diseños con repeticiones intencionales, pero no recurrencias entre piezas que indiquen códigos de comunicación visual y/o reglas ornamentales compartidas. En segundo lugar, once tipos se repiten a escala interartefacto: dos tipos se registraron en cuatro artefactos, tres en tres artefactos y seis en dos artefactos, cuyas reiteraciones sí pueden sugerir cierta circulación de información y/o preferencia ornamental (tabla 5).

Arte mobiliar en escala regional: vínculos entre la colección bajo estudio y otras placas grabadas provenientes del golfo San Matías

Tal como mencionamos más arriba, las nueve placas de la colección del GSM provienen de cuatro localidades arqueológicas: Bajo de la Quinta $(n=4)$, Punta Pórfido $(n=1)$, Saco Viejo $(n=2)$ y San Antonio Oeste $(n=2)$. En trabajos previos se han publicado datos sobre un total de diez placas provenientes de San Antonio Oeste (zona \#11 en la base de datos de Patagonia a escala macrorregional), de las cuales nueve están grabadas: por lo tanto, éstas constituyen el marco de referencia comparativo espacialmente más relevante para la colección bajo estudio (Sanchez-Albornóz 1961; Losada Gómez 1980; Ceresole 2008; Acevedo 2015). Las nueve placas de zona \#11 están decoradas con un total de 49 tipos, de los cuales 13 son compartidos con las nueve placas del GSM presentadas en este trabajo (cuyo repertorio total es de 48 tipos). Esto implica que ambas colecciones comparten un grado de similitud comparativamente bajo (27\% de sus repertorios) y un alto grado de variabilidad de diseños decorativos entre ambos conjuntos.

Dentro de los TM compartidos predominan los que incluyen reticulados oblicuos (reticulado oblicuo, reticulado oblicuo en franja, reticulado oblicuo en guarda, tablero de reticulado oblicuo, triángulos en guarda rellenos con reticulado oblicuo); los que incluyen líneas rectas (línea recta, líneas rectas paralelas, líneas rectas paralelas múltiples, líneas rectas paralelas rellenas con líneas rectas oblicuas); la clepsidra rellena con reticulado; el reticulado ortogonal; los guiones paralelos múltiples y el zigzag (figura 4). 


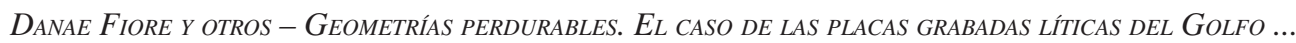

Tabla 5. Tipos de motivos repetidos entre los artefactos de la colección del GSM

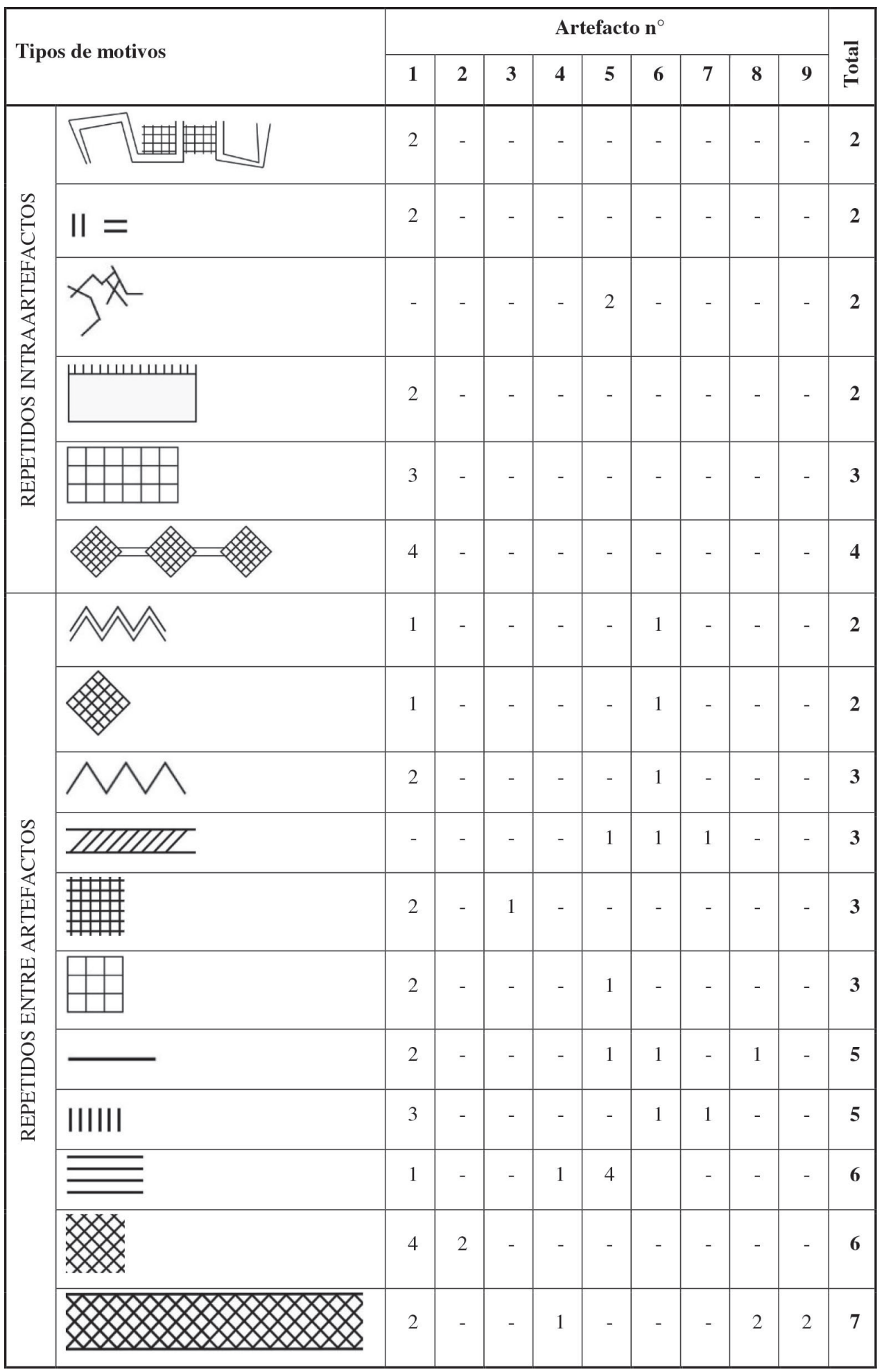




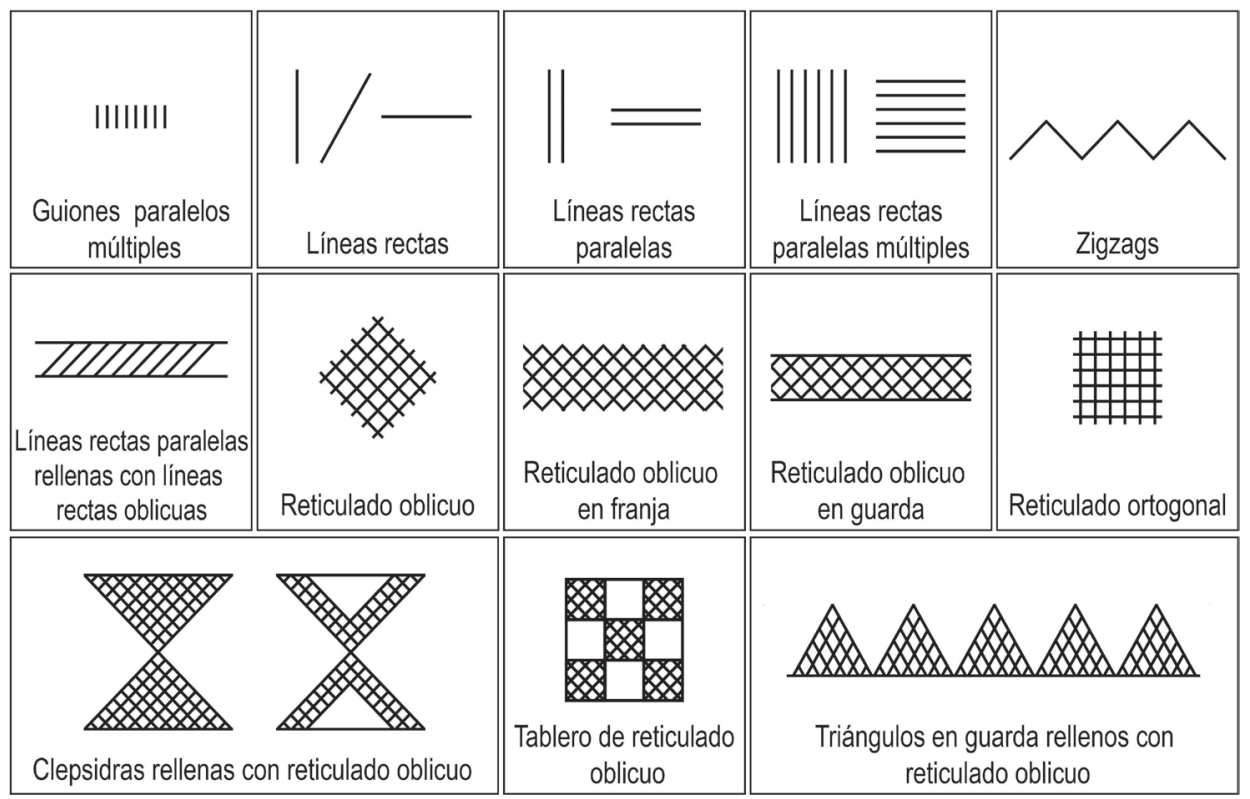

Figura 4. TM compartidos entre las placas del GSM y San Antonio Oeste (zona \#11)

La comparación respecto de la estructuración de los diseños muestra que las placas de la zona \#11 tienen una importante diversidad (clase I: $n=4$; clase III: $n=2$; clase IV: $n=3$ ). La comparación con las placas de GSM muestra más divergencias que recurrencias, ya que en dicha muestra predomina ampliamente la estructuración de clase IV.

Respecto de los tamaños de las placas (solo las enteras; $n=3$ ), es evidente la alta variabilidad, pero resulta notorio que éstas tienen en común la tendencia hacia superficies (alto por ancho) por debajo de los $90 \mathrm{~mm}^{2}$, existiendo pocos casos de mayor tamaño (todos provenientes de la zona \#11, lo cual es estadísticamente esperable ya que es la que presenta más casos enteros).

En síntesis, la comparación entre estas dos muestras, que tienen procedencias coincidentes y que están constituidas por nueve placas cada una, muestra más variabilidad que recurrencias tanto en los TM como en estructuras de diseño y tamaños. Si bien no es posible afirmar que las placas hayan sido producidas donde se las ha registrado arqueológicamente, esto sugiere que la contigüidad espacial en la zona de depositación/descarte de las piezas no habría sido un factor altamente influyente sobre las características de su decoración. Por el contrario, lo que habría primado es la producción y circulación de diseños variados, bajo una regla laxa relativa al uso del grabado para producir motivos geométricos rectilíneos. Veremos a continuación si estas mismas tendencias se verifican a escala macrorregional.

Arte mobiliar en Patagonia y más allá: vínculos entre la colección bajo estudio y otras placas grabadas a escala macro-regional

En esta sección comparamos los datos de la muestra de nueve placas grabadas del GSM con la información de la base de datos macrorregional que incluye muestras de un total de veintidós zonas, tanto de Patagonia ${ }^{3}$ como de Pampa y Sierras Centrales (figura 5). Se registra información sobre 170 placas grabadas y un repertorio total de 337 TM decorativos. Al comparar este repertorio con los 48 TM que decoran las nueve placas del GSM se evidencia que la colección bajo estudio 
comparte 31 tipos con las placas a escala macrorregional, que constituyen 64,5\% del repertorio del GSM y 9,2\% del repertorio general macrorregional. Los restantes 17 TM son exclusivos de la colección GSM y no son compartidos con ninguna otra región.

Los TM más frecuentes de la muestra de 170 placas son: líneas rectas $(n=575)$; zigzags $(\mathrm{n}=211)$; líneas rectas paralelas $(\mathrm{n}=156)$; líneas $\mathrm{V}(\mathrm{n}=125)$; líneas curvas $(\mathrm{n}=120)$; líneas rectas paralelas múltiples $(n=117)$ y reticulado oblicuo en guarda $(n=105)$. De estos tipos, hay algunos que son relativamente frecuentes en las placas del GSM: los reticulados oblicuos en guarda $(n=7)$; las líneas rectas paralelas múltiples $(n=6)$, las líneas rectas $(n=5)$ y los zigzags $(n=3)$; resulta importante recordar que la muestra es de nueve artefactos, por lo cual las frecuencias de TM siempre serán comparativamente bajas.

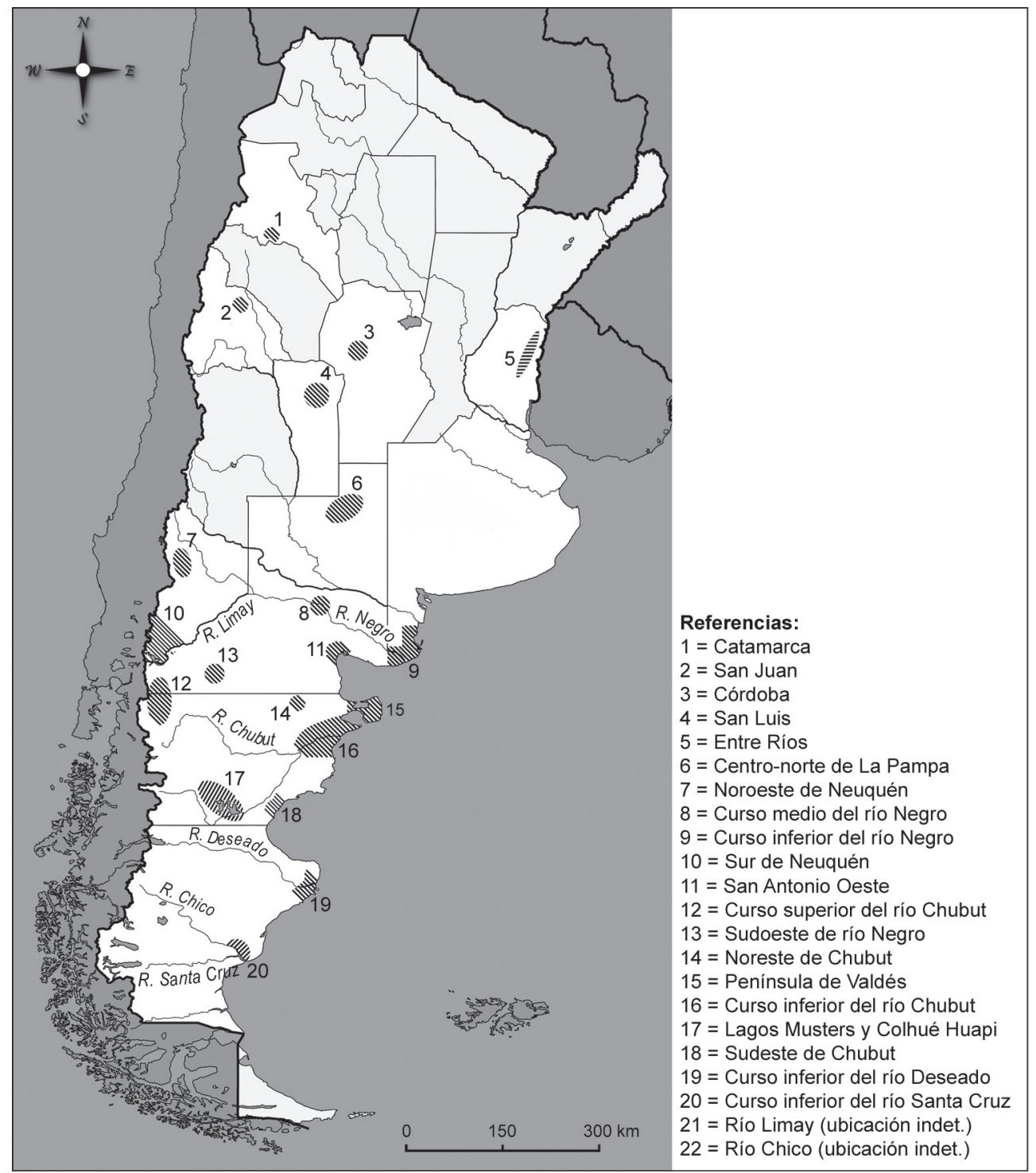

Figura 5. Zonas de proveniencia de las placas grabadas registradas en la base de datos macrorregional (sensu Acevedo 2015) 
Los potenciales vínculos de las placas grabadas del GSM y las de otras zonas de Patagonia, Pampa y/o Sierras Centrales fueron analizados mediante dos procedimientos distintos. El primero opera partiendo desde la colección bajo estudio para compararla con la información de la base de datos macrorregional. Así, se buscó en cuántos otros artefactos se registraron los TM más frecuentes del GSM y de qué zonas proceden éstos, con el objeto de evaluar la distribución espacial de estos tipos, tomada como proxy para el análisis de potenciales interacciones a escala macrorregional. Para ello se tomaron los TM que aparecen en tres o más artefactos de la muestra analizada, lo cual incluye un total de cinco tipos. De esta manera se pudo constatar que estos tipos presentan frecuencias muy variadas y con distribuciones espaciales disímiles (figura 5; tabla 6) ${ }^{4}$ : 1) el tipo guiones paralelos múltiples (GUI PP M) se registra en 10 artefactos de la muestra macro-regional, que provienen de 8 zonas;

2) el tipo línea recta (LN R) se registra en 110 artefactos de la muestra macrorregional, que provienen de 16 zonas;

3) el tipo líneas rectas paralelas múltiples (LNS RS PP M) se registra en 42 artefactos de la muestra macrorregional, que provienen de 14 zonas;

4) el tipo líneas rectas paralelas rellenas con líneas rectas oblicuas (LNS RS PP RLL C/ LNS RS $\mathrm{OBL}$ ) se registra en 5 artefactos de la muestra macrorregional, que provienen de 5 zonas; $\mathrm{y}$

5) el tipo reticulado oblicuo en guarda (RT OBL GDA) se registra en 22 artefactos de la muestra macrorregional, que provienen de 11 zonas.

Estos resultados demuestran que los TM más frecuentes del GSM evidencian un alto contacto entre zonas, ya que la circulación de tipos compartidos abarca diecinueve zonas (de un total de veintidós). La frecuencia de artefactos decorados con estos TM es muy variada, ya que va desde un solo artefacto hasta trece, como mínimo (tabla 6). ${ }^{5}$ Resultan destacables las coincidencias de los tipos: líneas rectas paralelas rellenas con líneas rectas oblicuas (LNS RS PP RLL C/ LNS RS OBL) y reticulado oblicuo en guarda (RT OBL GDA), que, por su comparativa complejidad de diseño, requieren particular atención en su reproducción de un artefacto a otro, implicando así una intencionalidad en el mantenimiento de las formas, potencialmente para garantizar la comunicación de contenidos y/o para sostener reglas ornamentales comunes. Asimismo, es relevante notar que, más allá de la zona \#11, que comparte su espacialidad con el GSM, las mayores coincidencias de TM compartidos son: a) con las zonas \#9 (curso inferior del río Negro), \#15 (Península Valdés), \#16 (curso inferior del río Chubut), \#19 (curso inferior del río Deseado) y \#20 (curso inferior del río Santa Cruz), que implican relaciones con otras zonas costeras al norte y al sur de la zona bajo estudio; b) con las zonas \#10 (sur de Neuquén) y \#12 (curso superior del río Chubut), que implican relaciones con zonas andinas, a latitudes similares a las zonas costeras; y c) con las zonas \#4 (San Luís) y \#6 (centro-norte de La Pampa), que implican relaciones con zonas distantes, extrapatagónicas. Estos datos, sin embargo, deben ser tomados con precaución dado que algunos de estos TM son de diseño sencillo y cabe la posibilidad de la existencia de convergencias azarosas entre las decoraciones de estos artefactos. Por esta razón, para contrarrestar este potencial sesgo, se desarrolló otro procedimiento de análisis contextual.

El segundo procedimiento realizado para contextualizar la muestra del GSM a escala macrorregional, fue tomar como indicador de circulación de diseños e interacción entre personas, la repetición de 31 TM identificados como diagnósticos en la muestra de 170 placas decoradas de Patagonia y regiones adyacentes (del repertorio total de $337 \mathrm{TM}^{6}$; Acevedo 2015). Debido a la complejidad de sus diseños, estos TM tienen pocas posibilidades de ser producto de convergencias azarosas y, por lo tanto, su aparición en el registro arqueológico de zonas diversas tiene más chances de responder a procesos de interacción. Este procedimiento opera de manera contraria al anterior: parte de la base de datos macrorregional hacia la colección bajo estudio. Así, de los 31 TM diagnósticos, se registraron ocho de ellos en la colección de artefactos del GSM analizada en este trabajo (tabla 6). Estos son: 
1) clepsidra rellena con reticulado (CLP RLL C/ RT), que se registra en las zonas \#9 (curso inferior del río Negro; n=1), \#10 (sur de Neuquén; n=1) y \#11 (San Antonio Oeste; n=2);

2) escaleriforme cerrado relleno con reticulado oblicuo (ESC CRD RLL C/ RT OBL), que se registra en las zonas \#4 (San Luís; $n=1$ ) y \#12 (curso superior del río Chubut; $n=1$ );

3) rombos adosados (RBOS ADS), que se registra en las zonas \#7 (noroeste de Neuquén; n=1) y \#9 (curso inferior del río Negro; $n=1$ );

4) rectángulo relleno con reticulado oblicuo (RCT RLL C/ RT OBL), que se registra en las zonas \#9 (curso inferior del río Negro n=2), \#10 (sur de Neuquén; n=1) y \#19 (curso inferior del río Deseado; $\mathrm{n}=1)$;

5) tablero simple (TB), que se registra en las zonas \#6 (centro-norte de La Pampa; n=1) y \#12 (curso superior del río Chubut; $\mathrm{n}=1$ );

6) tablero con reticulado oblicuo (TB RT OBL), que se registra en las zonas \#6 (centro-norte de La Pampa; $\mathrm{n}=1$ ), \#11 (San Antonio Oeste; n=2) y \#15 (Península Valdés; n=1);

7) guarda de triángulos rellenos con reticulado oblicuo (TR GDA RLL C/ RT OBL), que se registra en las zonas \#6 (centro-norte de La Pampa; $\mathrm{n}=1$ ), \#9 (curso inferior del río Negro; n=2), \#10 (sur de Neuquén; n=1), \#11 (San Antonio Oeste; n=2) y \#16 (curso inferior del río Chubut; $n=1)$;

8) zigzag cerrado (ZZCRD), que se registra en las zonas \#4 (San Luís; $n=1$ ), \#6 (centro-norte de La Pampa; $\mathrm{n=1}$ ), \#9 (curso inferior del río Negro; $\mathrm{n}=1$ ) y \#16 (curso inferior del río Chubut; $\mathrm{n}=1$ ).

Esta información evidencia que la muestra bajo estudio, además de compartir tres TM diagnósticos con la zona \#11 (San Antonio Oeste), que forma parte del GSM, comparte TM diagnósticos con otras nueve zonas, aunque en muy bajas cantidades (uno o dos artefactos; figura 5). Así, se verifican las siguientes tendencias:

1) con la zona \#9 (curso inferior del río Negro) comparte cinco TM diagnósticos, lo cual es esperable porque es una de las zonas más próximas;

2) con la zona \#6 (centro-norte de La Pampa) comparte cuatro TM diagnósticos, lo cual es llamativo en tanto que se trata de una zona más distante;

3) con la zona \#10 (sur de Neuquén) comparte tres TM diagnósticos, lo cual es llamativo por su distancia y porque se trata de una región cordillerana, localizada en un paisaje netamente distinto al de la costa rionegrina;

4) con las zonas \#4 (San Luis), \#12 (curso superior del río Chubut) y \#16 (curso inferior del río Chubut) comparte dos TM diagnósticos; en los dos primeros casos se trata de zonas lejanas y con paisajes distintos al GSM, mientras que la zona \#16 es una región comparativamente menos lejana y parcialmente costera, mostrando así afinidades paisajísticas con el GSM;

5) con las zonas \#7 (noroeste de Neuquén), \#15 (Península Valdés) y \#19 (curso inferior del río Deseado) comparte un solo TM diagnóstico.

Al combinar los resultados obtenidos mediante ambos procedimientos comparativos (TM más frecuentes en la muestra bajo estudio y TM diagnósticos de la base de datos de Patagonia y regiones adyacentes) resulta notorio que hay una importante consistencia en varias de las zonas que registran TM compartidos (figura 6). Así, las zonas \#9, \#15 y \#16, que son de la vertiente atlántica de Patagonia, registran motivos compartidos de ambos grupos (los más frecuentes y los diagnósticos). Lo mismo ocurre con las zonas \#10 y \#12, lo cual resulta de particular interés ya que se trata de regiones del sector andino de Patagonia, es decir, no solamente distantes, sino de entornos ecológicos y paisajísticos distintos a los costeros (figura 6). A su vez, también se registran algunos casos de TM diagnósticos y TM más frecuentes compartidos en la zona \#19 (curso inferior del río Deseado), también de la vertiente atlántica, aunque mucho más distante y en la zona \#07 (noroeste de Neuquén), que está ubicada en la zona andina patagónica (figura 6). Así, incluso a pesar del tamaño pequeño de algunas de las muestras, la trayectoria de circulación de estos diseños visuales evidencia que habrían existido vías de contacto de norte a sur por la costa atlántica patagónica y de este a oeste entre costa y cordillera. 


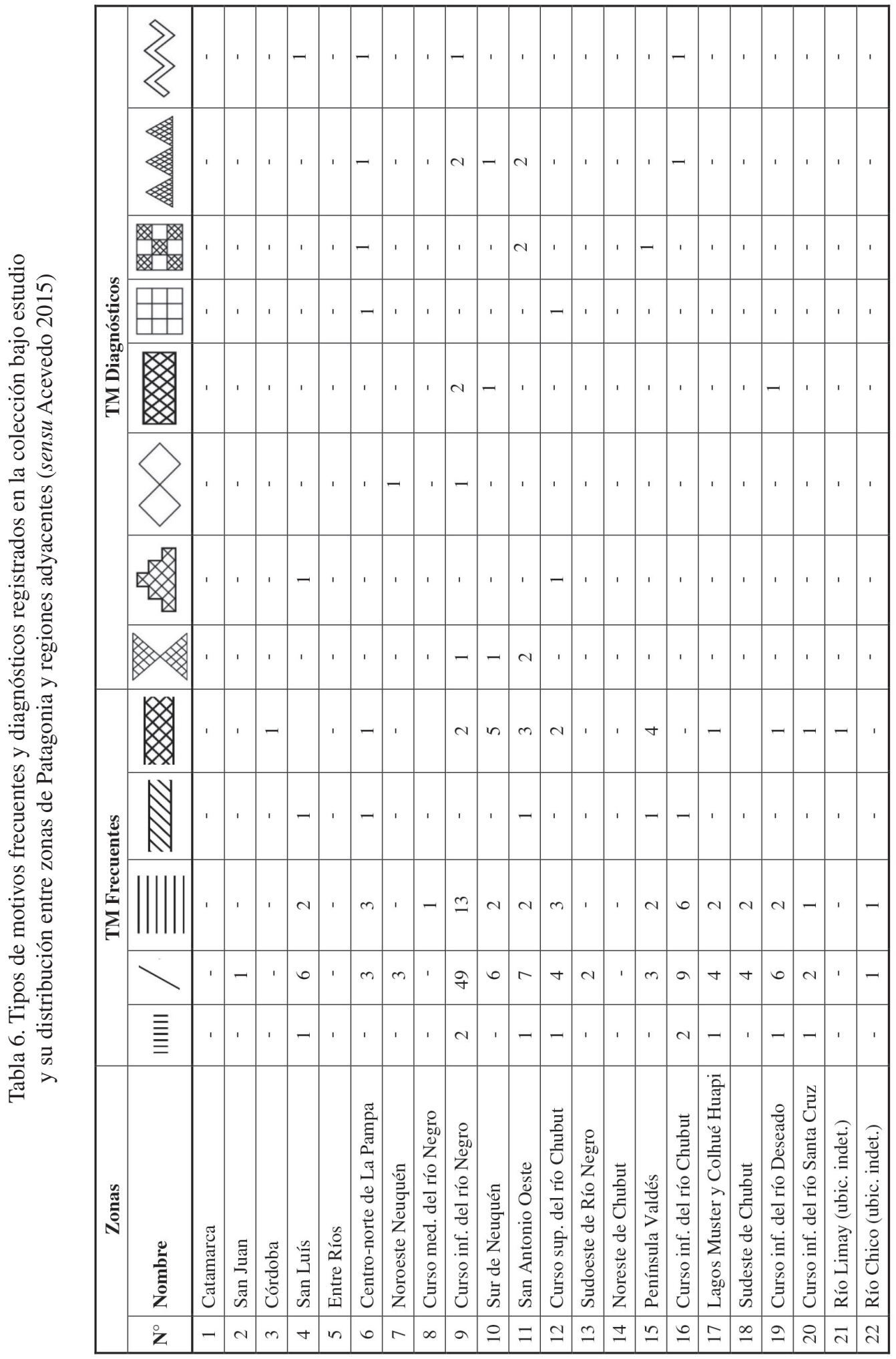


Llamativamente, los artefactos de la muestra bajo estudio comparten muy pocos TM o ninguno (sean frecuentes o diagnósticos), con tres zonas comparativamente próximas al GSM: la zona \#8 (curso medio del río Negro), \#13 (sudoeste de Río Negro) y \#14 (noreste de Chubut) (figura 6). Si bien no puede descartarse la existencia de sesgos potenciales asociados al tamaño de las muestras de dichas zonas (zona \#8 = dos placas; zona \#13 = tres placas y zona \#14 = una placa), estos resultados implicarían que la circulación de TM no habría sido espacialmente lineal, sino más compleja. En tal sentido, los TM del GSM se comparten con zonas próximas costeras y también con zonas distantes tanto costeras como andinas, pero "salteándose" otras zonas intermedias que registran placas grabadas, pero con otros TM. Sin embargo, no pueden descartarse la influencia de sesgos debido al pequeño tamaño de la muestra analizada. Por otro lado, la muestra bajo estudio registra también casos de TM diagnósticos compartidos con las zonas \#6 (centro-norte de La Pampa) y \#4 (San Luis), lo cual resulta interesante en tanto que demuestra alguna forma de interacción con áreas extrapatagónicas al norte del río Colorado.

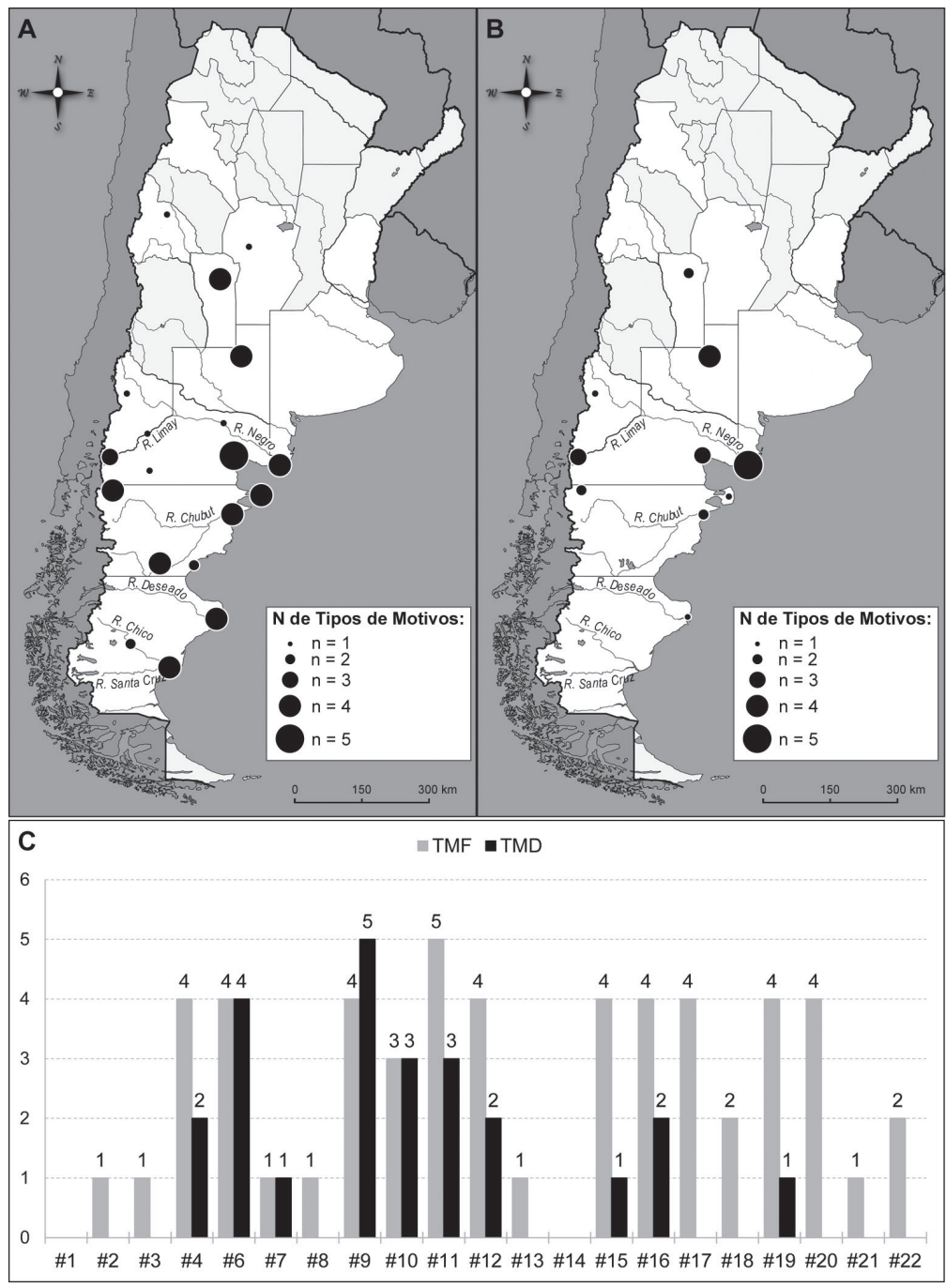

Figura 6. N de TM compartidos entre la muestra analizada y las restantes zonas: (a) TM frecuentes; (b) TM diagnósticos; (c) TM frecuentes y diagnósticos comparados 


\section{DISCUSIÓN Y CONCLUSIONES}

Los análisis aquí presentados aportan información novedosa tanto a escala del GSM, como a escala macrorregional. Resulta de particular interés retomar algunos resultados para evaluar sus implicaciones acerca de la producción y circulación de diseños decorativos sobre soportes móviles en Patagonia. Primero, la colección de placas del GSM se inserta de manera coherente con la información preexistente respecto de las 170 placas anteriormente analizadas (Acevedo 2015). Esta coherencia se registra en la presencia de motivos geométricos rectilíneos, con ángulos predominantemente ortogonales y agudos, grabados mediante incisión sobre una o ambas caras de la placa, con formas de estructuración previamente conocidas en Patagonia. El repertorio del GSM comparte una alta proporción de TM a escala macrorregional, implicando una estandarización morfológica entre piezas de regiones distintas. Sin embargo, la repetición de TM (es decir, la reiteración de motivos con una misma morfología) dentro y entre piezas es consistentemente baja, tanto en el GSM como a escala interregional. Más aún, la combinación de TM nunca es igual, ni tampoco lo son su disposición y estructuración en las caras y bordes de las placas, produciendo piezas similares, pero de diseños únicos.

Ahora bien, tal como se mencionó en el marco teórico, la estandarización en la morfología de TM, así como de su repetición, combinación y estructuración pueden arrojar luz sobre las funciones ornamentales y comunicativas de las imágenes. Retomando el modelo propuesto, una alta estandarización en todas las variables mencionadas implicaría una función ornamental estructurada o bien una función comunicativa de alta redundancia (que representa un mensaje de manera reiterativa). En el extremo contrario, una baja estandarización en las variables, implicaría una función comunicativa de baja redundancia (alta heterogeneidad de contenidos no reiterados) o bien un bajo grado de codificación de la información (con posible ambigüedad y polisemia). En nuestro caso de estudio, la estandarización se restringe a algunos de los TM que componen el repertorio y que se comparten en distintas regiones. La baja repetición de TM entre piezas y regiones; la baja combinación de los mismos TM en dos o más piezas, y la nula existencia de diseños idénticos (compuestos con los mismos TM y las mismas clases de estructuración), son compatibles con la existencia de procesos de comunicación de baja redundancia.

Esta heterogeneidad compositiva implica, además, la posibilidad de que si se trató de imágenes representativas, la interpretación de los mensajes haya requerido altos niveles de conocimiento de los repertorios, ya que es posible que lo más significativo de la imagen haya sido cada motivo en sí mismo y que las reglas de composición hayan sido muy laxas (Acevedo 2015; Acevedo y Fiore 2020). Por otra parte, si se tratara de imágenes ornamentales, no habrían estado sujetas a reglas estéticas rigurosas y socialmente compartidas, sino que habrían respondido a pautas que habrían permitido e incluso estimulado la expresión individual, tal como se ha observado en otros conjuntos de arte mobiliar (Fiore 2012).

Finalmente, nuestro análisis ha permitido establecer claras relaciones espaciales entre la muestra de placas del GSM y otras regiones de Patagonia (y extrapatagónicas). Así, los TM más frecuentes del GSM y/o los más diagnósticos generalmente convergen en marcar los mismos patrones. Los vínculos espaciales se manifiestan en: a) zonas del litoral atlántico, tal como el GSM: curso inferior del río Negro, Península Valdés, curso inferior del río Chubut y cuso inferior del río Deseado; b) zonas andinas tales como el sur de Neuquén, el norte de Neuquén y el curso superior del río Chubut; c) zonas distantes al GSM, como San Luis, el centro-norte de La Pampa, y el curso inferior del río Santa Cruz. Llamativamente, no se manifiestan en regiones próximas al GSM como el curso medio del río Negro, el sudoeste de Río Negro y el noreste de Chubut.

La información arqueológica sobre otras líneas de evidencia apoya estos contactos interregionales. En las localidades San Antonio Oeste y Saco Viejo se registran tipos de obsidiana procedentes del norte de Chubut y sur de Neuquén (Favier Dubois et al. 2009b). En los alrede- 
dores de San Antonio Oeste se halló un fragmento de punta lanceolada muy similar a las típicas de las Sierras Centrales (Córdoba y San Luis) (Rivero y Heider 2017; Pautassi y Sario 2018). En Saco Viejo se han hallado: a) artefactos confeccionados sobre cuarcitas que afloran en el Sistema Serrano de Tandilia (Formación Balcarce); b) cuentas verdosas de mineral de cobre (probablemente malaquita) con potencial procedencia en La Pampa, Neuquén o Mendoza (Gómez Otero 2003; Berón 2012); c) cuentas confeccionadas en gasterópodos del género Megalobulimus, de distribución tropical/subtropical, que alcanzan la provincia de Córdoba donde se registran cuentas muy similares a las recuperadas en Saco Viejo (ver Gordillo 2018). Las regiones centro-este, surpampeana y norpatagónica también comparten un estilo similar de cerámica incisa (Catella 2017; Di Prado 2018). Finalmente, diseños de grabados rupestres hallados en Punta Odriozola (muy cercana a Punta Pórfido) poseen similitudes con algunos registrados en la meseta de Santa Cruz (Carden y Borella 2015); sin embargo, éstos no guardan similitudes con el repertorio de TM de las placas grabadas.

En cuanto a las placas, lo que se comparte entre estas regiones son TM y no diseños completos: este panorama espacial sugiere que lo que habría circulado sería la unidad mínima de producción gráfica e información visual, que es el motivo. Como vimos más arriba, el diseño de cada motivo -analíticamente clasificado como TM- podría haber tenido significado propio y/o valor decorativo independientemente de su combinación con otros TM.

La importante inversión laboral implicada en la producción de estas imágenes grabadas sobre soportes duraderos y transportables, la consistencia en la producción de sus diseños recurrentemente geométricos, pero no muy estandarizados y la amplia distribución espacial de algunos TM específicos alejan la posibilidad de que estas creaciones fueran ornamentaciones basadas en normas estéticas o de procesos de comunicación de alta redundancia. Contrariamente, el panorama fáctico que hemos construido permite sugerir que estas formas de arte mobiliar son compatibles con procesos de comunicación más complejos, en los cuales se habría manifestado visualmente una gran diversidad de contenidos de manera poco redundante, altamente heterogénea y con baja regulación social. Este sistema habría estimulado la variedad de diseños.

Esta diversidad de diseños, puntuada por algunos TM compartidos, habría contribuido a sostener relaciones socioeconómicas a larga distancia entre grupos cazadores-recolectores de Patagonia, Pampa y Sierras Centrales, con quienes no necesariamente se habría compartido la lengua, y con quienes habría sido eficiente compartir un conjunto de pautas visuales básicas, pero suficientemente laxas como para facilitar la interacción. Los medios visuales para esa interacción circularon inscriptos en estas geometrías perdurables.

\section{AGRADECIMIENTOS}

A los pobladores de San Antonio Oeste que amablemente facilitaron piezas para este estudio, Betty Díaz, Luis Giuliani, Raúl González y Maite Narvarte. A los/las evaluadores/as cuyos comentarios y sugerencias enriquecieron el trabajo. Los proyectos PIP CONICET (6415 y 0756) y PICT 2013-1128 financiaron las investigaciones y campañas arqueológicas que permitieron el hallazgo de placas grabadas in situ.

\section{NOTAS}

1 En trabajos recientes, Lynch et al. (2019) y Cassiodoro et al. (2019) han publicado nuevos ejemplares de placas grabadas que aún no han sido incluidos en la base de datos.

2 Estos motivos puntiformes parecen horadados. Ahora bien, cuando hay elementos puntiformes que forman 
parte de otros motivos, como los triángulos, parecen realizados por percusión directa. Estas determinaciones técnicas se dificultan por la pátina blanca que cubre los motivos y serán analizadas en mayor detalle en el futuro.

3 En la base de datos, la zona \#11 corresponde a San Antonio Oeste, e incluye las nueve placas decoradas registradas en la bibliografía que presentamos en la sección anterior.

4 En la tabla 6 los datos presentados se concentran exclusivamente en los casos de placas que tienen asignación a alguna de las veintidós zonas; los casos de procedencia indeterminable por ausencia de información publicada (ver Acevedo 2015) no han sido tomados en cuenta en este conteo.

5 El N de 49 artefactos con el TM línea recta (LN R) debe tomarse con cautela debido a que proviene de registros gráficos dibujados de placas decoradas (Losada Gómez 1980), cuyo nivel de precisión y detalle no asegura que por lo menos algunos de ellos puedan en realidad haber sido pequeñas grietas u otro tipo de marcas en los artefactos y no partes del diseño decorativo.

6 La definición de estos TM se realizó tomando en cuenta todos los detalles gráficos de la morfología de cada motivo. Esto registra de manera realista la gran variabilidad que caracteriza a estas piezas, pero simultáneamente genera un gran número de tipos, que, en rigor, podrían considerarse como "sub-tipos" ya que, en varios casos, sostienen altos grados de similitud entre sí y difieren precisamente en los mencionados detalles (Acevedo 2015).

\section{REFERENCIAS BIBLIOGRÁFICAS}

Acevedo, A. (2015). Hachas grabadas, placas grabadas y comunicación visual suprarregional entre grupos cazadores-recolectores de finales del holoceno tardío. Relaciones de la Sociedad Argentina de Antropología 40(2): 589-620.

Acevedo, A. (2016). Motivos dispersos. Un examen de la distribución geográfica de los motivos presentes en la decoración de hachas y placas grabadas de Patagonia, Pampa y regiones adyacentes. En F. Oliva, A. M. Rocchietti y F. Solomita (eds.), Imágenes Rupestres. Lugares y regiones: 83-108. Rosario Facultad de Humanidades y Artes, Universidad Nacional de Rosario.

Acevedo, A. y D. Fiore (2020). Imágenes, códigos y comunicación: un análisis del arte rupestre en el Extremo Sur del Macizo del Deseado (Patagonia, Argentina). Arqueología 26(2): 127-155.

Ameghino, F. [1880] (1947). La antigüedad del hombre en el Plata. Buenos Aires, Editorial Intermundo.

Aschero, C. (1988). Pinturas rupestres, actividades y recursos naturales; un encuadre arqueológico. En: H. Yacobaccio (ed.), Arqueología Contemporánea Argentina. Actualidad y Perspectivas: 109-145. Buenos Aires, Ediciones Búsqueda.

Barrientos, G., M. Leipus y F. Oliva (1997). Investigaciones arqueológicas en la laguna de Los Chilenos (provincia de Buenos Aires). En M. Berón y G. Politis (eds.), Arqueología de la Región Pampeana en la década de los '90: 115-125. San Rafael, Museo de Historia Natural de San Rafael e INCUAPA.

Barrientos, G. y S. I. Perez (2004). La expansión y dispersión de poblaciones del norte de Patagonia durante el Holoceno tardío: evidencia arqueológica y modelo explicativo. En M. T. Civalero, P. Fernández y G. Guráieb (eds.), Contra Viento y Marea. Arqueología de la Patagonia: 179-195. Buenos Aires, INAPL-SAA.

Belardi, J. B. (2004). Más vueltas que una greca. En M. T. Civalero, P. Fernández y G. Guráieb (eds.), Contra Viento y Marea. Arqueología de la Patagonia: 591-603. Buenos Aires, INAPL-SAA.

Berón, M. (1997). Mobility and subsistence in a semidesert environment. The Curacó river basin (La Pampa, Argentina). En J. Rabassa y M. Salemme (eds.), Quaternary of South America and Antarctic Peninsula (10): 133-166. Holanda, Balkema Publishers. 
DANAE Fiore Y OtRos - GEOMETRÍAS PERDURABLES. El CASO DE LAS PLACAS GRABADAS LítICAS DEL GOLFO ...

Berón, M. (2006). Relaciones interétnicas e identidad social en el registro arqueológico. Género y Etnicidad en la Arqueología Sudamericana. Serie teórica 4:119-138.

Berón, M. (2012). Cuentas de collar verdes: materias primas, contextos y significación en un cementerio de cazadores-recolectores de La Pampa (Argentina). En W. Wiesheu y G. Guzzy (coords.), El jade y otras piedras verdes: perspectivas interdisciplinarias e interculturales: 197-226. México, INAH.

Borella F., M. Cadillo, C. M. Favier Dubois y J. Alberti (2015). Nuevas investigaciones arqueológicas entre Punta Pórfido y Punta Odriozola: implicancias para el entendimiento de la dinámica de las ocupaciones humanas en la costa oeste del golfo San Matías (Río Negro). Relaciones de la Sociedad Argentina de Antropología 40(1): 233-252.

Bórmida, M. (1952). Pampidos y Australoides: Coherencias ergológicas y míticas. Archivos Ethnos 6: 5182.

Cabrera, A. L. y A. Willink (1980). Biogeografía de América Latina. Washington D.C., OEA Monographs.

Carden, N. (2004). Valga la redundancia. Arte rupestre e información en el Macizo del Deseado. En M. T. Civalero, P. Fernández y G. Guráieb (eds.), Contra Viento y Marea. Arqueología de la Patagonia: 613-625. Buenos Aires, INAPL-SAA.

Carden, N. y F. Borella (2015). Symbols by the sea: the first recording of atlantic coastal rock art in patagonia (Punta Odriozola, Río Negro, Argentina). Rock Art Research 32(2): 146-162.

Carden, N. y E. Borges Vaz (2017). El arte mobiliar. En G. Martínez (ed.), Arqueología de cazadores recolectores del curso inferior del río Colorado (provincia de Buenos Aires, Argentina). Aportes al conocimiento de las ocupaciones humanas Pampeano-Patagónicas: 211-229. Olavarría, INCUAPACONICET-UNICEN.

Carden, N. y G. Martínez (2014). Diseños fragmentados. Circulación social de imágenes sobre huevos de rheidae en pampa y norpatagonia. Boletín del Museo Chileno de Arte Precolombino 19(2): 55-75.

Cassiodoro, G., F. Guichón y A. Re (2019). Diseños sobre soportes móviles y comunicación en el centrooeste de Santa Cruz durante el Holoceno tardío. En J. Gómez Otero, A. Svoboda y A. Banegas (eds.), Arqueología de la Patagonia: el pasado en las arenas: 29-40. Puerto Madryn, Instituto de Diversidad y Evolución Austral.

Catella, L. (2017). La tecnología cerámica en la cuenca del Arroyo Chasicó. Una aproximación a la movilidad de las sociedades del Holoceno tardío de Patagonia nororiental y de la región pampeana sudeste, Argentina. Magallania 45(1): 137-163.

Ceresole, G. (2008). Base de datos de placas grabadas. En M. Fernández (comp.), Rastros. Arqueología e historia de la cuenca del río Limay, vol. 2: 288-469. Buenos Aires, CIAFIC. Formato CD.

Conkey, M. (1980). The Identification of Prehistoric Hunter-Gatherer Aggregation Sites: the case of Altamira. Current Anthropology 21(5): 609-630.

Curtoni, R. P. (2006). Expresiones simbólicas, cosmovisión y territorialidad en los cazadores-recolectores pampeanos. Relaciones de la Sociedad Argentina de Antropología 31: 133-160.

d'Errico, F. (1994). L'art gravé azilien: de la technique à la signification. Paris, CNRS éditions.

Di Prado, V. (2018). Prácticas alfareras prehispánicas y procesos de interacción social en el centro-este de Argentina durante el Holoceno tardío. Latin American Antiquity 29(3): 552-571. 
Dobres, M. A. (2001). Meaning in the making: agency and the social embodiment of technology and art. En M. Schiffer (ed.), Anthropological perspectives on technology: 47-76. Albuquerque, University of New Mexico Press.

Favier Dubois, C. M. (2013). Hacia una cronología del uso del espacio en la costa norte del golfo San Matías (Río Negro, Argentina): sesgos geológicos e indicadores temporales. En A. F. Zangrando, R. Barberena, A. Gil, G. Neme, M. Giardina, L. Luna, C. Otaola, S. Paulides, L. Salgán y A. Tívoli (comps.), Tendencias teórico-metodológicas y casos de estudio en la arqueología de Patagonia: 87-96. San Rafael, Museo de Historia Natural de San Rafael, SAA e INAPL.

Favier Dubois, C. M., F. Borella, y R. H. Tykot (2009a). Explorando tendencias temporales en el uso del espacio y los recursos marinos en el Golfo San Matías (Río Negro). En F. Santiago, M. Salemme, M. Alvarez, E. Piana, M. Vázquez y M. E. Mansur (comps.), Arqueología de Patagonia: una mirada desde el último confín, tomo 2: 985-997. Ushuaia, Editorial Utopías.

Favier Dubois, C. M. y R. Kokot (2011). Changing scenarios in Bajo de la Quinta (San Matías Gulf, Northern Patagonia, Argentina): Impact of geomorphologic processes in subsistence and human use of coastal habitats. Quaternary International 245(1):103-110.

Favier Dubois, C. M., Ch. Stern y M. Cardillo (2009b). Caracterización de la distribución y tipos de obsidiana presentes en la costa rionegrina. En F. Santiago, M. Salemme, M. Alvarez, E. Piana, M. Vázquez y M. E. Mansur (comps.), Arqueología de Patagonia: una mirada desde el último confín, tomo 1: 349-359. Ushuaia, Editorial Utopías.

Fernandez, J. (1982). Historia de la Arqueología Argentina. Anales de Arqueología y Etnología 34-35: 92199.

Fiore, D. (2006). Puentes de agua para el arte mobiliar: la distribución espacio-temporal de artefactos óseos decorados en Patagonia meridional y Tierra del Fuego. Cazadores-Recolectores del Cono Sur. Revista de arqueología I: 137-147.

Fiore, D. (2009). La materialidad del arte. Modelos económicos, tecnológicos y cognitivos visuales. En R. Berberena, K. Borrazzo y L. A. Borrero (eds.), Perspectivas Actuales en Arqueología Argentina: 1-25. Buenos Aires, IMHICIHU-CONICET.

Fiore, D. (2011). Materialidad visual y arqueología de la imagen. Perspectivas conceptuales y propuestas metodológicas desde el sur de Sudamérica. Boletín Del Museo Chileno De Arte Precolombino 16(2): 101119.

Fiore, D. (2012). Diseños y tempos en el arte mobiliar del Canal Beagle (Tierra del Fuego). Una exploración de los ritmos de cambio en la decoración de artefactos óseos. Relaciones de la Sociedad Argentina de Antropología 37(1): 183-206.

Fiore, D. (2020). The art of making images. Technological affordance, design variability and labour organization in the production of engraved artefacts and body paintings in Tierra del Fuego (Southern South America). Journal of Archaeological Method and Theory 27: 481-510.

Fiore, D. y F. Borella (2010). Geometrías delicadas. Diseños grabados en cáscaras de huevo de rheidae recuperados en la costa norte del golfo San Matías, Río Negro. Intersecciones en Antropología 11: 277-293.

Gamble, Clive S. (1982). Interaction and alliance in paleolithic society. Man 17: 92-107.

Guichón, F. (2018). Redes de información durante el Holoceno medio y Tardío en Patagonia meridional: estudio de las representaciones rupestres en la cuenca del lago Cardiel y sur de la meseta Strobel. Tesis Doctoral inédita, Facultad de Filosofía y Letras, Universidad de Buenos Aires. 
Danae Fiore y otros - Geometrías PerduRables. El CASO de las PLACAS GRABadas líticas del Golfo ...

Gómez Otero, J. (2003). Movilidad y contactos en la costa centro-norte de Patagonia argentina en tiempos pre y posthispánicos. En R. J. Mandrini y C. D. Paz (comps.), Las fronteras hispanocriollas del mundo latinoamericano en los siglos XVIII-XIX: 287-312. Buenos Aires, Universidad Nacional del Sur, Instituto de Estudios Histórico-Sociales, Universidad Nacional del Centro de la Provincia de Buenos Aires.

Gordillo, S. (2018). El caracol gigante Megalobulimus lorentzianus (Doering, 1876): una especie biocultural de la provincia de Córdoba. Revista de la Facultad de Ciencias Exactas, Físicas y Naturales 5(2): 63-69.

Gradin, C. (1973). La piedra pintada de Mamuel Choique (provincia de Río Negro). Relaciones de la Sociedad Argentina de Antropología 7: 145-157.

Gradin, C. (1978). Algunos aspectos del análisis de las manifestaciones rupestres. Revista del Museo Provincial de Neuquén 1: 120-137.

Hartley, R. J. (1992). Rock Art on the Northern Colorado Plateau: Variability in Content and Context. Aldershot, Avebury.

Hernández Llosas, M. I. (1985). Diseño de investigación para representaciones rupestres. PROINDARA: 9-65. Buenos Aires, INAPL, FECIC.

Heyd, T. (2014). Aesthetics in archaeology. En C. Smith (ed.), Encyclopedia of Global Archaeology: 38-42. Heidelberg, Springer.

Lehmann-Nistche, R. (1909). Hachas y placas para ceremonias procedentes de Patagonia. Revista del Museo de La Plata 16(3): 204-240.

Losada Gómez, H. (1980). Placas grabadas prehispánicas de Argentina. Madrid, Biblioteca Prehistórica Hispana.

Lynch V., J. Vargas Gariglio y D. Daniel Terranova Enrique (2019). Engraved stone plaquettes from the North Patagonian area (Somuncurá plateau, Río Negro, Argentina) and the use of different microscopic techniques for their analysis. World Archaeology 50(1): 104-125.

Menghin, O. F. (1957). Los estilos del arte rupestre de Patagonia. Acta Prehistórica 1: 57-87.

Oliva, F. (2006). Uso y contextos de producción de elementos "simbólicos" del sur y oeste de la provincia de Buenos Aires, República Argentina (Área Ecotonal Húmeda Seca Pampeana). Revista de la Escuela de Antropología 12: 101-116.

Outes, F. F. (1916). Las placas grabadas de Patagonia. Examen crítico del material conocido y descripción de nuevos ejemplares. Revista de la Universidad de Buenos Aires 32: 611-624.

Pautassi, E. A. y G. M. Sario (2018). Diseños y materias primas: discutiendo la variabilidad de las puntas de proyectil lanceoladas del noroeste de Córdoba. Anales de Arqueología y Etnología 73(1): 41-58.

Rivero, D. y G. Heider (2017). Morfometría geométrica en puntas de proyectil lanceoladas de las Sierras Centrales, Argentina. Revista del Museo de Antropología 10: 75-82.

Sanchez-Albornóz, N. (1961). Hachas y placas de San Antonio Este (Río Negro). Runa 5: 455-464.

Zubimendi, M., L. Zilio y H. Hammond (2016). Los objetos adorno-colgantes y artefactos decorados de la costa norte de Santa Cruz (Patagonia, Argentina). En F. Oliva, A. M. Rocchietti y F. Solomita (eds.), Imágenes Rupestres. Lugares y regiones: 525-536. Facultad de Humanidades y Artes, Universidad Nacional de Rosario 
